NBER WORKING PAPER SERIES

\title{
UTILIZATION-ADJUSTED TFP ACROSS COUNTRIES: MEASUREMENT AND IMPLICATIONS FOR INTERNATIONAL COMOVEMENT
}

\author{
Zhen Huo \\ Andrei A. Levchenko \\ Nitya Pandalai-Nayar \\ Working Paper 26803 \\ http://www.nber.org/papers/w26803 \\ NATIONAL BUREAU OF ECONOMIC RESEARCH \\ 1050 Massachusetts Avenue \\ Cambridge, MA 02138 \\ February 2020, Revised November 2020
}

The time series for the utilization-adjusted TFP estimates by country and sector are available for download online. We are grateful to the editors (Loukas Karabarbounis and Urban Jermann), an anonymous referee, David Baqaee, Chris Boehm, Lorenzo Caliendo, Yongsung Chang, Gabe Chodorow-Reich, Olivier Coibion, Javier Cravino, Emmanuel Farhi, John Fernald, Jesus Fernandez-Villaverde, Simon Gilchrist, Felipe Saffie, Kang Shi, Alireza Tahbaz-Salehi, Linda Tesar and seminar participants at various institutions for helpful comments, and to Barthélémy Bonadio and Jaedo Choi for superb research assistance. The views expressed herein are those of the authors and do not necessarily reflect the views of the National Bureau of Economic Research.

NBER working papers are circulated for discussion and comment purposes. They have not been peer-reviewed or been subject to the review by the NBER Board of Directors that accompanies official NBER publications.

(C) 2020 by Zhen Huo, Andrei A. Levchenko, and Nitya Pandalai-Nayar. All rights reserved. Short sections of text, not to exceed two paragraphs, may be quoted without explicit permission provided that full credit, including $\odot$ notice, is given to the source. 
Utilization-Adjusted TFP Across Countries: Measurement and Implications for International Comovement

Zhen Huo, Andrei A. Levchenko, and Nitya Pandalai-Nayar

NBER Working Paper No. 26803

February 2020, Revised November 2020

JEL No. F41,F44

\section{ABSTRACT}

This paper develops estimates of TFP growth adjusted for movements in unobserved factor utilization for a panel of 29 countries and up to 37 years. When factor utilization changes are unobserved, the commonly used Solow residual mismeasures actual changes in TFP. We use a general equilibrium dynamic multi-country multi-sector model to derive a production function estimating equation that corrects for unobserved factor usage. We compare the properties of utilization-adjusted TFP series to the standard Solow residual, and quantify the roles of both TFP and utilization for international business cycle comovement. Utilization-adjusted TFP is virtually uncorrelated across countries, and does not generate much GDP comovement through its propagation. Shocks to factor utilization can more successfully account for international comovement.

Zhen Huo

Department of Economics

Yale University

New Haven, CT 06520

zhen.huo@yale.edu

Andrei A. Levchenko

Department of Economics

University of Michigan

611 Tappan Street

Ann Arbor, MI 48109

and CEPR

and also NBER

alev@umich.edu
Nitya Pandalai-Nayar

Department of Economics

University of Texas at Austin

3.142 BRB, 2225 Speedway

Austin, TX 78713

and NBER

npnayar@utexas.edu 


\section{Introduction}

It has long been acknowledged in macroeconomics that the intensity of factor utilization varies over the business cycle. When some dimensions of variable factor utilization are not directly observed, conventional ways of inferring TFP changes, such as the Solow residual, can be misleading as measures of technology shocks. Thus, estimation of TFP shocks must account for variation in unobserved factor usage. Following the seminal work of Basu, Fernald, and Kimball (2006, henceforth BFK), it has become standard to use a utilization-adjusted series as a measure of TFP when studying the US economy. Importantly, BFK show that the utilization-adjusted TFP series have substantially different properties than the traditional Solow residual.

However, studies of international business cycles have typically employed the Solow residual as the measure of technology shocks. This approach makes it challenging to study the sources of international business cycle comovement in general, and to isolate the role of technology shocks in particular. Variable factor utilization in a country could respond to TFP shocks originating abroad. Non-technology shocks that produce a utilization response will also appear in the measured Solow residual.

Our first contribution is to develop utilization-adjusted TFP series for a sample of 29 countries, 30 sectors, and up to 37 years. To guide the estimation, we present a theoretical framework in which capital utilization rates, hours per worker, and workers' effort are endogenous and can vary within a period in response to shocks. The model yields an estimating equation that features a correction for unobserved factor utilization. The first main result is that utilization-adjusted TFP is virtually uncorrelated across countries. This is in contrast to the Solow residual, which is modestly positively correlated. Our findings imply that the cross-country correlation in the Solow residual typically found in the literature is in fact due to correlated movements in unobserved factor utilization.

Our second contribution is to quantify the roles of TFP and factor utilization in the international business cycle. A feature of our modeling and estimation approach is that we can explicitly separate the impacts of TFP and utilization on GDP comovement. We use the model structure to extract a utilization shock, that rationalizes movements in utilization conditional on the world vectors of TFP shocks and pre-determined variables, and world general equilibrium. While we do not microfound the utilization shock, it shock captures the effects of all non-TFP shocks on utilization rates. We then assess how much GDP comovement can be generated with TFP and utilization shocks. Our second main finding is that TFP shocks alone cannot generate much GDP correlation when fed into a multi-country, multi-sector general equilibrium model of production and trade. In the G7 countries, TFP shocks account for less than $10 \%$ of the observed GDP correlation on average. In the full 29-country sample, they produce zero GDP correlation on average. By contrast, utilization shocks are correlated, and generate about one-third of observed GDP comovement. 
We thus conclude that the common approach in the international business cycle literature of working with TFP-shock-driven fluctuations is not the most promising way to fully understand international comovement. By contrast, non-technology shocks that move factor utilization conditional on TFP are considerably more important as a driver of comovement.

We estimate the production function parameters using the theoretically-founded estimating equation and data on many countries and sectors from the KLEMS database (O'Mahony and Timmer, 2009). The key intuition behind this approach comes from BFK: agents optimize multiple dimensions of factor use intensity simultaneously. Thus, an observed dimension of factor utilization - hours per worker - can serve as a proxy for unobserved dimensions of factor utilization such as worker effort. To account for the endogeneity of inputs to TFP we build instruments that combine oil shocks and military expenditures with the input-output network. Our quantification uses a multi-country, multi-sector model of world production and trade in both intermediate inputs and final goods. We calibrate all the country-sector input and final expenditure shares using the World Input-Output Database (Timmer et al., 2015).

Our paper contributes to the empirical and quantitative literature on international business cycle comovement. A number of papers are dedicated to documenting international correlations in productivity shocks and inputs (e.g. Imbs, 1999; Kose, Otrok, and Whiteman, 2003; Ambler, Cardia, and Zimmermann, 2004). Also related is the body of work that identifies technology and demand shocks in a VAR setting and examines their international propagation (e.g. Canova, 2005; Corsetti, Dedola, and Leduc, 2014; Levchenko and Pandalai-Nayar, 2020). Relative to these papers, we use sector-level data to provide novel estimates of utilization-adjusted TFP shocks, and expand the sample of countries. A large research agenda builds models in which fluctuations are driven by productivity shocks, and asks under what conditions those models can generate observed international comovement (see, among many others, Backus, Kehoe, and Kydland, 1992; Heathcote and Perri, 2002). In these analyses, productivity shocks are proxied by the Solow residual, which we show can be misleading. Our quantitative assessment benefits from improved measurement of TFP shocks.

Our estimation belongs to the family of methods that measure factor utilization. Complementing the more model-based approaches such as BFK and Fernald (2014), other work has considered survey-based direct measures of plant capacity utilization (e.g. Shapiro, 1989; Gorodnichenko and Shapiro, 2011; Boehm and Pandalai-Nayar, 2019), or used other observable proxies such as electricity consumption (e.g. Burnside, Eichenbaum, and Rebelo, 1995). The alternative methods cannot be straightforwardly applied in our setting, as utilization surveys and electricity usage are not available for the large sample of countries, sectors, and years in our analysis. Our indirect measures of utilization are modestly positively correlated with the survey-based measures in the subset of countries and sectors for which those exist, although caution in such comparisons is important, as the questions on the surveys vary and do not closely correspond to the theoretical margin in our model. 
A literature in closed-economy macroeconomics going back to Greenwood, Hercowitz, and Huffman (1988) studies the implications of variable factor utilization for domestic business cycles (see, among many others, Bils and Cho, 1994; Cooley, Hansen, and Prescott, 1995; Gilchrist and Williams, 2000; Fair, 2018; Chodorow-Reich, Karabarbounis, and Kekre, 2019). Closely related to the focus of BFK, Shapiro (1993) finds that variations in capital's workweek explain much of the cyclicality of TFP. Our paper builds on this literature by assessing the implications of utilization adjustments to TFP for international GDP comovement.

The rest of the paper is organized as follows. Section 2 sets out a simple accounting framework that illustrates the potentially confounding role of unobserved factor utilization in studying international comovement due to TFP shocks. Section 3 presents the theory behind our estimation approach. The results of the estimation are in Section 4. We assess the importance of TFP and utilization for international comovement in a general-equilibrium framework in Section 5. Section 6 concludes.

\section{TFP and the Solow Residual in International Comovement}

Factor usage, TFP, and the Solow residual Let there be $J$ sectors indexed by $j$ and $N$ countries indexed by $n$. Let gross output $Y_{n j t}$ in sector $j$ country $n$ be given by:

$$
Y_{n j t}=Z_{n j t}\left(K_{n j t}^{\alpha_{j}} L_{n j t}^{1-\alpha_{j}}\right)^{\eta_{j}} X_{n j t}^{1-\eta_{j}}
$$

where $Z_{n j t}, K_{n j t}, L_{n j t}$, and $X_{n j t}$ are TFP, capital, labor, and materials inputs, respectively. For simplicity, input elasticities $\alpha_{j}$ and $\eta_{j}$ are assumed to vary by sector in the baseline, but allowed to vary by country, sector and time in Appendix A.2.

When it comes to measurement, it is important that $K_{n j t}$ and $L_{n j t}$ are utilization-adjusted inputs that may not be directly observable to the econometrician. Let the factor inputs be comprised of:

$$
K_{n j t} \equiv U_{n j t} M_{n j t}, \quad \text { and } \quad L_{n j t} \equiv E_{n j t} H_{n j t} N_{n j t} .
$$

The capital input is the product of the quantity of installed capital ("machines") $M_{n j t}$ that can be measured in the data, and capital utilization $U_{n j t}$ that is not directly observable. Similarly, the true labor input is the product of the number of workers $N_{n j t}$, hours per worker $H_{n j t}$, and labor effort $E_{n j t}$. While $N_{n j t}$ and $H_{n j t}$ can be obtained from existing datasets, $E_{n j t}$ is unobservable.

The Solow residual $S_{n j t}$ nets out observable factor usage from gross output:

$$
d \ln S_{n j t} \equiv d \ln Y_{n j t}-\alpha_{j} \eta_{j} d \ln M_{n j t}-\left(1-\alpha_{j}\right) \eta_{j} d \ln H_{n j t}-\left(1-\alpha_{j}\right) \eta_{j} d \ln N_{n j t}-\left(1-\eta_{j}\right) d \ln X_{n j t} .
$$


The Solow residual thus contains the following components:

$$
d \ln S_{n j t} \equiv \underbrace{d \ln Z_{n j t}}_{\text {True TFP }}+\underbrace{\alpha_{j} \eta_{j} d \ln U_{n j t}+\left(1-\alpha_{j}\right) \eta_{j} d \ln E_{n j t}}_{\text {Unobserved utilization }} .
$$

This expression makes it transparent that in this setting, the Solow residual can diverge from the true TFP shock due to unobserved utilization of inputs.

GDP accounting and the aggregates Following national accounting conventions, real GDP at time $t$, evaluated at base prices (prices at $t-1$ ) is defined by:

$$
Y_{n t}=\sum_{j=1}^{J}\left(P_{n j t-1} Y_{n j t}-P_{n j t-1}^{X} X_{n j t}\right)
$$

where $P_{n j t-1}$ is the gross output base price, and $P_{n j t-1}^{X}$ is the base price of inputs in that sectorcountry.

Approximating growth rates with log differences, the real GDP change between $t-1$ and $t$ is then:

$$
d \ln Y_{n t}=\sum_{j=1}^{J} D_{n j t-1}\left(d \ln Y_{n j t}-\left(1-\eta_{j}\right) d \ln X_{n j t}\right),
$$

where $D_{n j t-1} \equiv \frac{P_{n j t-1} Y_{n j t-1}}{Y_{n t-1}}$ is sector $j$ 's base period Domar weight, that is, the sector's gross sales as a fraction of aggregate value added.

Combining (2.1) and (2.3) leads to aggregate TFP:

$$
d \ln Z_{n t}=\sum_{j=1}^{J} D_{n j t-1} d \ln Z_{n j t} .
$$

The aggregate Solow residual can be written as:

$$
d \ln S_{n t}=\sum_{j=1}^{J} D_{n j t-1} d \ln S_{n j t}=d \ln Z_{n t}+d \ln \mathcal{U}_{n t}
$$

where in the second equality, $d \ln \mathcal{U}_{n t}$ is the aggregated $\log$ change in unobserved utilization:

$$
d \ln \mathcal{U}_{n t} \equiv \sum_{j=1}^{J} D_{n j t-1}\left\{\alpha_{j} \eta_{j} d \ln U_{n j t}+\left(1-\alpha_{j}\right) \eta_{j} d \ln E_{n j t}\right\}
$$

Appendix B.1 details the derivations behind all the equations in this section. 
Implications for international comovement The covariance in the Solow residual between countries $n$ and $m$ is:

$$
\sigma\left(S_{n}, S_{m}\right)=\sigma\left(Z_{n}, Z_{m}\right)+\sigma\left(\mathcal{U}_{n}, \mathcal{U}_{m}\right)+\sigma\left(Z_{n}, \mathcal{U}_{m}\right)+\sigma\left(Z_{m}, \mathcal{U}_{n}\right)
$$

where $\sigma(x, y) \equiv \operatorname{Cov}\left(d \ln x_{t}, d \ln y_{t}\right)$.

The observed Solow residual can be correlated across countries both due to correlated TFP shocks, and due to correlated unobserved input changes. This leads to two distinct problems with using the Solow residual to study international comovement. The first is that $\mathcal{U}_{n}$ may be responding endogenously to technology shocks. If input use in country $m$ responds to TFP shocks in country $n$, Solow residuals in $n$ and $m$ will become correlated even if true TFP is not. Using Solow residuals will then lead the researchers to attribute GDP comovement to correlated productivity shocks rather than shock transmission.

The second problem is shocks to input usage $\mathcal{U}_{n}$ itself. If the economy is subject to non-technology shocks that affect input usage directly, the Solow residual will reflect the correlation and transmission of non-technology, rather than technology shocks.

It is an empirical question to what degree correlations in the Solow residual reflect true technology shock correlation, as opposed to endogenous transmission or non-technology shocks. It is clear, however, that using the Solow residual as a measure of technology shocks can lead to incorrect assessments both of the relative importance of correlated shocks vs. endogenous transmission, and of the relative importance of technology vs. non-technology shocks for international comovement. To make progress, we need to overcome the measurement challenge of estimating true TFP when utilization-adjusted factor usage is unobserved.

\section{Variable Factor Utilization Model}

We now set up a multi-country, multi-sector framework with variable factor utilization. The model has two principal uses. The first is to derive an estimating equation that can be used to infer TFP in an environment with unobserved factor utilization. The second is quantification of the roles of TFP and variable utilization in international comovement, that we undertake in Section 5 after estimating the TFP series.

Households Each country $n$ is populated by a representative household. The household consumes the final good available in country $n$ and supplies labor and capital to firms. There is a continuum 
of workers in the household who share the same consumption. The problem of the household is

$$
\max _{\substack{\left\{M_{n j t}\right\},\left\{N_{n j\}}\right\},\left\{H_{n j t}\right\},\left\{E_{n j t}\right\},\left\{U_{n j t}\right\}}} \mathbb{E}_{0} \sum_{t=0}^{\infty} \beta^{t} \Psi\left(C_{n t}-\sum_{j} \xi_{n j t} N_{n j t} G_{j}\left(H_{n j t}, E_{n j t}, U_{n j t}\right)-\sum_{j} N_{n j t}^{\psi^{n}}\right)
$$

subject to

$$
\begin{aligned}
P_{n t}\left(C_{n t}+\sum_{j} I_{n j t}\right) & =\sum_{j} W_{n j t} N_{n j t} H_{n j t} E_{n j t}+\sum_{j} R_{n j t} U_{n j t} M_{n j t} \\
M_{n j t+1} & =\left(1-\varrho_{j}\right) M_{n j t}+I_{n j t}
\end{aligned}
$$

where $C_{n t}$ is consumption and $I_{n j t}$ is investment, both of which are bundles of goods coming from different countries and sectors. The total efficiency units of labor supplied in a sector is $E_{n j t} H_{n j t} N_{n j t}$, and the total efficiency units of capital supplied is $U_{n j t} M_{n j t}$. Labor collects a sector-specific wage $W_{n j t}$, and capital is rented for the price $R_{n j t}$. The variable $\xi_{n j t}$ captures potential preference shocks that shift factor supplies.

We assume the following functional form for $G_{j}($.$) :$

$$
G_{j}(H, E, U)=H^{\psi_{j}^{h}}+E^{\psi_{j}^{e}}+U^{\psi_{j}^{u}}
$$

We highlight three features of the household problem. First, labor and capital are differentiated by sector, as the household supplies factors to, and accumulates capital in, each sector separately. In this formulation, labor and capital are neither fixed to each sector nor fully flexible. As $\psi_{j}^{\iota} \rightarrow 1$, $\iota=h, e, u$, factor supply across sectors becomes more sensitive to factor price differentials. In the limit, households supply variable factors only to the sector offering the highest factor price. At the opposite extreme, as $\psi_{j}^{\iota} \rightarrow \infty$, the supply of hours, effort, and capital utilization is fixed in each sector by the preference parameters.

Second, we assume that the number of employed workers $N_{n j t}$ and machines $M_{n j t}$ in a sector is predetermined. This is required in order to have a well-defined notion of variable utilization. While this approach is standard for machines, it is less common for employment, where it is usually assumed that hours and employment move in parallel. Specifically, in our model the number of workers in a particular sector has to be chosen before observing the current shocks as in Burnside, Eichenbaum, and Rebelo (1993), reflecting the fact that it takes time to adjust the labor force. ${ }^{1}$ On the other

\footnotetext{
${ }^{1}$ Our assumption implies that there are frictions that limit the substitutability of employment and the workweek. This assumption can be supported by the data. For instance, in our sample the standard deviations of hours per worker growth and of employment growth are 0.02 and 0.06 respectively, suggesting the two margins should not be treated symmetrically.
} 
hand, within a period households can choose the hours $H_{n j t}$ and effort $E_{n j t}$ that change the effective amount of labor supply, and utilization rates $U_{n j t}$ that change the effective amount of capital supply. These margins capture the idea that utilization rates of factor inputs typically vary over the business cycle. Our framework thus implies that within a period, labor and capital supply to each sector are upward-sloping (e.g. Christiano, Motto, and Rostagno, 2014).

Third, our formulation of the disutility of the variable factor supply (3.2) is based on the Greenwood, Hercowitz, and Huffman (1988, henceforth GHH) preferences for labor and a similar isoelastic formulation of the utilization cost of capital. The GHH preferences mute the interest rate effects and income effects on the choice of hours, effort, and utilization rates, which helps to study the properties of the static equilibrium where the number of machines and employees are treated as exogenous.

Firms To make the estimation more reliable, we follow BFK and allow for potentially non-constant returns to scale in production. Ex post, our estimates show that returns to scale are close to constant, and thus it is not a large force empirically or quantitatively. A representative firm in sector $j$ in country $n$ operates a CRS production function

$$
Y_{n j t}=Z_{n j t} \Theta_{n j t}\left(K_{n j t}^{\alpha_{j}} L_{n j t}^{1-\alpha_{j}}\right)^{\eta_{j}} X_{n j t}^{1-\eta_{j}}
$$

where $K_{n j t}$ and $L_{n j t}$ are the true capital and labor inputs as in (2.2), and the total factor productivity $Z_{n j t} \Theta_{n j t}$ is taken as given by the firm. The intermediate input bundle $X_{n j t}$ is an aggregate of inputs from potentially all countries and sectors.

The total factor productivity consists of two parts: the exogenous shocks $Z_{n j t}$ and the endogenous component:

$$
\Theta_{n j t}=\left(\left(K_{n j t}^{\alpha_{j}} L_{n j t}^{1-\alpha_{j}}\right)^{\eta_{j}} X_{n j t}^{1-\eta_{j}}\right)^{\gamma_{j}-1}
$$

where $\gamma_{j}$ controls possible congestion or agglomeration effects. As a result, the sectoral aggregate production function is:

$$
Y_{n j t}=Z_{n j t}\left[\left(K_{n j t}^{\alpha_{j}} L_{n j t}^{1-\alpha_{j}}\right)^{\eta_{j}} X_{n j t}^{1-\eta_{j}}\right]^{\gamma_{j}}
$$

Optimality conditions The households' intra-temporal optimization problem leads to

$$
H_{n j t} G_{j h}\left(H_{n j t}, E_{n j t}, U_{n j t}\right)=E_{n j t} G_{j e}\left(H_{n j t}, E_{n j t}, U_{n j t}\right) .
$$

Under the functional form adopted for $G_{j}(\cdot)$, this condition implies that the choice of effort has a log-linear relationship with the choice of hours:

$$
d \ln E_{n j t}=\frac{\psi_{j}^{h}}{\psi_{j}^{e}} d \ln H_{n j t} .
$$


A similar expression can be derived for the relationship between the optimal choice of capital utilization and the optimal choice of hours:

$$
\frac{H_{n j t} G_{j, h}\left(H_{n j t}, E_{n j t}, U_{n j t}\right)}{U_{n j t} G_{j, u}\left(H_{n j t}, E_{n j t}, U_{n j t}\right)}=\frac{W_{n j t} L_{n j t}}{R_{n j t} K_{n j t}} .
$$

We know from the firms' problem that the right-hand side of the equation above is equal to the ratio of output elasticities $\alpha_{j} /\left(1-\alpha_{j}\right)$, which is a constant. As a result, the utilization rate also has a log-linear relationship with hours worked:

$$
d \ln U_{n j t}=\frac{\psi_{j}^{h}}{\psi_{j}^{u}} d \ln H_{n j t}
$$

up to a normalization constant.

The properties (3.6)-(3.7) capture the idea that flexible inputs tend to move jointly in the same direction. The household intra-temporal first-order conditions therefore allow us to express unobserved effort and capital utilization as a log-linear function of observed hours:

$$
\alpha_{j} d \ln U_{n j t}+\left(1-\alpha_{j}\right) d \ln E_{n j t}=\zeta_{j} d \ln H_{n j t},
$$

where $\zeta_{j}=\alpha_{j} \frac{\psi_{j}^{h}}{\psi_{j}^{u}}+\left(1-\alpha_{j}\right) \frac{\psi_{j}^{h}}{\psi_{j}^{e}}$.

Estimating equation Log-differencing (3.5), and separating the observed and the unobserved components of input usage yields:

$$
\begin{aligned}
d \ln Y_{n j t}= & \gamma_{j} \underbrace{\left(\alpha_{j} \eta_{j} d \ln M_{n j t}+\left(1-\alpha_{j}\right) \eta_{j} d \ln \left(H_{n j t} N_{n j t}\right)+\left(1-\eta_{j}\right) d \ln X_{n j t}\right)}_{\text {Observed Inputs }} \\
& +\gamma_{j} \underbrace{\left(\alpha_{j} \eta_{j} d \ln U_{n j t}+\left(1-\alpha_{j}\right) \eta_{j} d \ln E_{n j t}\right)+d \ln Z_{n j t}}_{\text {Unobserved Inputs }} .
\end{aligned}
$$

This equation makes it plain that measuring TFP innovations is difficult because the intensity with which factors are used in production varies over the business cycle, and cannot be directly observed by the econometrician. As unobserved factor utilization will respond to TFP innovations, it is especially important to account for it in estimation, otherwise factor usage will appear in estimated TFP.

Plugging (3.8) into (3.9) yields the following estimating equation:

$$
\begin{aligned}
d \ln Y_{n j t}= & \delta_{j}^{1}\left(\alpha_{j} \eta_{j} d \ln M_{n j t}+\left(1-\alpha_{j}\right) \eta_{j} d \ln \left(H_{n j t} N_{n j t}\right)+\left(1-\eta_{j}\right) d \ln X_{n j t}\right) \\
& +\delta_{j}^{2} d \ln H_{n j t}+\delta_{n j}+d \ln Z_{n j t} .
\end{aligned}
$$


The country $\times$ sector fixed effects $\delta_{n j}$ allow for country-sector specific trend output growth rates, that can be driven by either trend TFP or trend factor accumulation. We take out these trend differences, since we are interested in comovement of business cycles.

The coefficient $\delta_{j}^{1}$ is clearly an estimate of returns to scale $\gamma_{j}$. Equation (3.8) provides a structural interpretation for the coefficient $\delta_{j}^{2}=\gamma_{j} \eta_{j} \zeta_{j}$. Conditional on the coefficient estimates and the $\log$ changes in the observed inputs, we obtain the TFP shocks $d \ln Z_{n j t}$ as residuals.

Our estimating equation and the factor use optimality condition (3.8) coincide with BFK. The key insight of BFK is that agents' static optimization imposes a relationship between the intensities of observed and unobserved input uses. This insight is more general than the model above. Indeed, BFK derive the same estimating equation in a partial-equilibrium setting without specifying the details of household choices or dynamics. In BFK, the choice between effort, utilization rates, and hours is made by firms facing upward-sloping supply curves of these dimensions of factor inputs. In contrast, we model the trade-off between these margins as being faced by households. Fully articulating a model as we do here has the benefit of showing that the BFK structural equation applies in a fairly general open economy setting that can easily be nested in standard general-equilibrium IRBC models. Our approach thus has the advantage of being simultaneously consistent with the econometric TFP estimation and with model-based quantification in world general equilibrium, allowing us to move seamlessly between the two. Though our framework is less general than BFK in some dimensions, an additional advantage is that we do not have to assume ad hoc convex cost functions for firm choices.

\section{Estimation}

\subsection{Identification}

The estimation proceeds to regress real output growth on the growth of the composite observed input bundle and the change in hours per worker. Because input usage will move with TFP shocks $d \ln Z_{n j t}$, the regressors in (3.10) are correlated with the residual. To overcome this endogeneity problem, we combine country-level sources of exogenous variation with the input-output network to build a set of instruments that are plausibly orthogonal to true TFP shocks but have predictive power for changes in production.

The first source of country-level variation is oil shocks, constructed using the approach in Hamilton (1996). An oil shock is defined as the difference between the log oil price and the maximum $\log$ oil price in the preceding four quarters. This oil price shock is either zero, or is positive when this difference is positive, reflecting the notion that oil prices have an asymmetric effect on output. The annualized oil shock is the sum over the four quarters of the preceding year. The second source of exogenous variation is the growth rate in real government defense spending, lagged by one year. 
Our instruments are first- and second-order indices of exposure to these aggregate shocks through the input network, following Acemoglu, Akcigit, and Kerr (2016). Specifically, a sector's first-order exposure to the oil shock is computed as the aggregate oil shock $O I L_{t}$ times the share of the sector's expenditure on oil as an input: $\mathcal{O}_{n j t}=O I L_{t} \times \sum_{m, i=o i l} \pi_{m i, n j}^{x}$. A sector's first-order exposure to the defense spending shock is $\mathcal{D}_{n j t}=D E F_{n t} \times \frac{\mathcal{G}_{n j}}{Y_{n j}}$, where $D E F_{n t}$ is national defense spending and $\frac{\mathcal{G}_{n j}}{Y_{n j}}$ is the fraction of sales to the government in total sectoral sales. The resulting instruments vary at the country-sector-year level.

We next construct second-order network propagation shocks. Sectors purchase inputs from and sell output to potentially all other countries and sectors in the world. Therefore, output in a sector might also respond to the effect of the oil and defense shocks on its suppliers and customers. We can thus build four additional instruments, capturing the second-order upstream and downstream exposure of industries to oil and defense spending shocks. These instruments are constructed by weighting the country-sector oil or defense spending shocks with the sales shares (cost shares) of downstream (upstream) industries for each sector. ${ }^{2,3}$

Following BFK, to reduce the number of parameters to be estimated, we restrict $\delta_{j}^{2}$ to take only three values, according to a broad grouping of sectors: durable manufacturing, non-durable manufacturing, and all others. We similarly estimate a single returns-to-scale coefficient $\delta_{j}^{1}$ for each group. Appendix Table A6 shows that allowing for sector-specific returns-to-scale yields estimates that are insignificantly different from the pooled estimate in most cases. Finally, we restrict the production function estimation sample to the G7 countries, for which we have the longest time series. This tends to lead to the strongest instruments and most precisely estimated coefficients.

\subsection{Data}

The data requirements for estimating equation (3.10) are growth of real output and real inputs for a panel of countries, sectors, and years. The dataset with the broadest coverage of this information is KLEMS 2009 (O'Mahony and Timmer, 2009). ${ }^{4}$ This database contains gross output, value added,

\footnotetext{
${ }^{2}$ The upstream instruments for sector $j$, country $n$ are $\sum_{m, i} \pi_{m i, n j}^{x} \mathcal{O}_{m i t}$ and $\sum_{m, i} \pi_{m i, n j}^{x} \mathcal{D}_{m i t}$. The downstream instruments for sector $j$, country $n$ are $\sum_{m} \frac{\pi_{m n j}^{f} P_{m j}^{f} \mathcal{F}_{m j}}{P_{n j} Y_{n j}} \mathcal{O}_{m t}+\sum_{m i} \frac{P_{n j, m i} X_{n j, m i}}{P_{n j} Y_{n j}} \mathcal{O}_{m i t}$ and $\sum_{m} \frac{\pi_{m n j}^{f} P_{m j}^{f} \mathcal{F}_{m i}}{P_{n j} Y_{n j}} \mathcal{D}_{m t}+$ $\sum_{m, i} \frac{P_{n j, m i} X_{n j, m i}}{P_{n j} Y_{n j}} \mathcal{D}_{m i t}$, where $\mathcal{O}_{m t}$ is the oil shock times the share of oil in final expenditure, and $\mathcal{D}_{m t}$ is the defense shock times the share of government in final expenditure. The shares $\pi_{m i, n j}^{x}$ and $\pi_{m n j}^{f}$ and final expenditures $P_{m j}^{f} \mathcal{F}_{m j}$ are defined in Appendix B.2. Downstream exposure includes exposure through final sales to consumers in all countries.

${ }^{3}$ BFK face a similar identification problem when estimating the utilization-adjusted series for the US. They use an oil price shock, the growth in real defense spending, and a monetary policy shock identified in a VAR. Our instruments build on BFK by taking advantage of subsequent advances in the networks literature. A monetary policy instrument has a poor first stage for the countries in our sample.

${ }^{4}$ This is not the latest vintage of KLEMS, as there is a version released in 2016. Unfortunately, however, the 2016 version has a shorter available time series, as the data start in 1995, and also has many fewer countries. A consistent concordance between the two vintages is not possible without substantial aggregation.
} 
labor and capital inputs, as well as output and input deflators. In a limited number of instances, we supplemented the information available in KLEMS with data from the WIOD Socioeconomic Accounts, which contains similar variables. After data quality checking and cleaning, we retain a sample of 29 countries, listed in Appendix Table A1. The database covers all sectors of the economy at a level slightly more aggregated than the 2-digit ISIC revision 3, yielding, after harmonization, 30 sectors listed in Appendix Table A2. In the best cases we have 38 years of data, 1970-2007, although the panel is not balanced and many emerging countries do not appear in the data until the mid-1990s. Appendix Table A3 provides a precise mapping between all the variables we use and their KLEMS counterparts, and lists instances in which WIOD Socioeconomic Accounts were used to supplement KLEMS. Appendix Table A4 provides detailed definitions and underlying sources of the KLEMS data, and lists instances in which the national surveys have missing observations and thus data were imputed in the G7 countries. This is the case for the capital stock in Japan in some years, and for occasionally missing price growth data. O'Mahony and Timmer (2009) contains an exhaustive documentation of the KLEMS data.

The oil price series is the West Texas Intermediate, obtained from the St. Louis Fed's FRED database. Military expenditure comes from the Stockholm International Peace Research Institute (SIPRI). The construction of the upstream and downstream instruments and the quantitative analysis in Section 5 require information on the input linkages at the country-sector-pair level as well as on final goods trade. This information comes from the 2013 WIOD database (Timmer et al., 2015), which contains the global input-output matrix.

\subsection{Empirical Results}

Production function estimates Table 1 summarizes the results of estimating equation (3.10). The returns to scale parameters are around 1.05 in durable manufacturing, 1.17 in non-durable manufacturing, and 0.94 in the quite heterogeneous non-manufacturing sector. None are significantly different from constant returns to scale. The coefficient on hours per worker $\left(d \ln H_{n j t}\right)$ is significantly different from zero in two out of three industry groups, indicating that adjusting for unobserved utilization is important in the manufacturing industries.

We have multiple instruments and multiple endogenous variables in our estimation. The appropriate test statistic for diagnosing the weak instruments problem is the Sanderson-Windmeijer $F$ (SW-F), which is designed for such a setting. Appendix Table A5 reports the first-stage $F$ statistics for the baseline and alternative combinations of instruments. The SW-F statistics indicate that the

instruments are not weak. The SW- $F$ statistics are greater than 8 for all coefficients except $\delta_{j}^{1}$ in the non-durable manufacturing group, where it suggests the instruments are possibly weak (SW- $F$ of 5.8). We therefore assess the sensitivity of the non-durable manufacturing $\delta_{j}^{1}$ to alternative subsets 
of the six instruments. Compared to the baseline estimate of 1.17 for this coefficient, the median point estimate across all combinations of instruments is 1.23 , and the median $\mathrm{SW}-F$ is 9.7 , while the instrument combination with highest SW- $F$ of 12.16 yields a coefficient estimate of 1.2 . This suggests that the relatively low SW- $F$ when using all 6 instruments does not have an unduly large influence on the estimated coefficient, compared to instrument combinations for which the SW- $F$ is higher. ${ }^{5}$ Appendix Table A6 reports the production function estimates in which returns to scale are allowed to vary by sector.

TABle 1: Production Function Parameter Estimates

\begin{tabular}{lcc}
\hline Industry Group & $\begin{array}{c}\text { Returns to Scale } \\
\left(\delta_{j}^{1}\right)\end{array}$ & $\begin{array}{c}\text { Utilization Adjustment } \\
\left(\delta_{j}^{2}\right)\end{array}$ \\
\hline Durables & 1.049 & 0.435 \\
& $(.046)$ & $(.172)$ \\
Non-durable manufacturing & 1.172 & 1.48 \\
& $(.119)$ & $(.627)$ \\
Non-durable non-manufacturing & 0.938 & 1.128 \\
& $(.209)$ & $(.674)$ \\
\hline
\end{tabular}

Notes: This table reports the estimates of $\delta_{j}^{1}$ and $\delta_{j}^{2}$ in the three broad groups of sectors, along with the Driskoll-Kraay standard errors in parentheses. The instruments used are the first- and second-order oil and defense spending shocks, described in the text. The regressions include country-sector fixed effects. First stage diagnostics are reported in Appendix Table A5.

Utilization-adjusted TFP series Figure 1 plots the aggregate utilization-adjusted TFP series along with the Solow residual for all the countries in our sample. The data displayed in the Figure are available to download online. ${ }^{6}$ As found by BFK, in the US our utilization-adjusted TFP series is less volatile than the Solow residual. However, it turns out that for the large majority of countries the adjusted TFP series is more volatile. The mean (median) standard deviation of the TFP series is 0.037 (0.033), while for the Solow residual it is $0.019(0.017){ }^{7}$

\footnotetext{
${ }^{5} \mathrm{As}$ far as we are aware, there is no established weak instrument test for a setting with multiple instruments and multiple endogenous variables that also takes into account heteroscedasticity. Therefore, in addition to the SW- $F$ statistics appropriate for multiple instruments/endogenous variables we also report the Kleinbergen-Paap $F$ statistics, that account for heteroscedasticity.

${ }^{6}$ Throughout the paper, we report aggregate TFP and other values under constant Domar weights $D_{n j}$, that correspond to period averages. This is done for ease of comparison with the quantitative model, which is solved in deviations from steady state. None of the results change if we use time-varying Domar weights instead. The data available to the public includes sectoral TFP and both constant and time-varying Domar weights, so that the user can undertake their preferred aggregation.

${ }^{7}$ The relationship between the variance of the Solow residual and TFP is $\sigma_{S}^{2}=\sigma_{Z}^{2}+\sigma_{\mathcal{U}}^{2}+2 \sigma_{Z, \mathcal{U}}$. The Solow residual can be less volatile than TFP if the covariance between TFP and utilization is sufficiently negative. The key finding of
} 


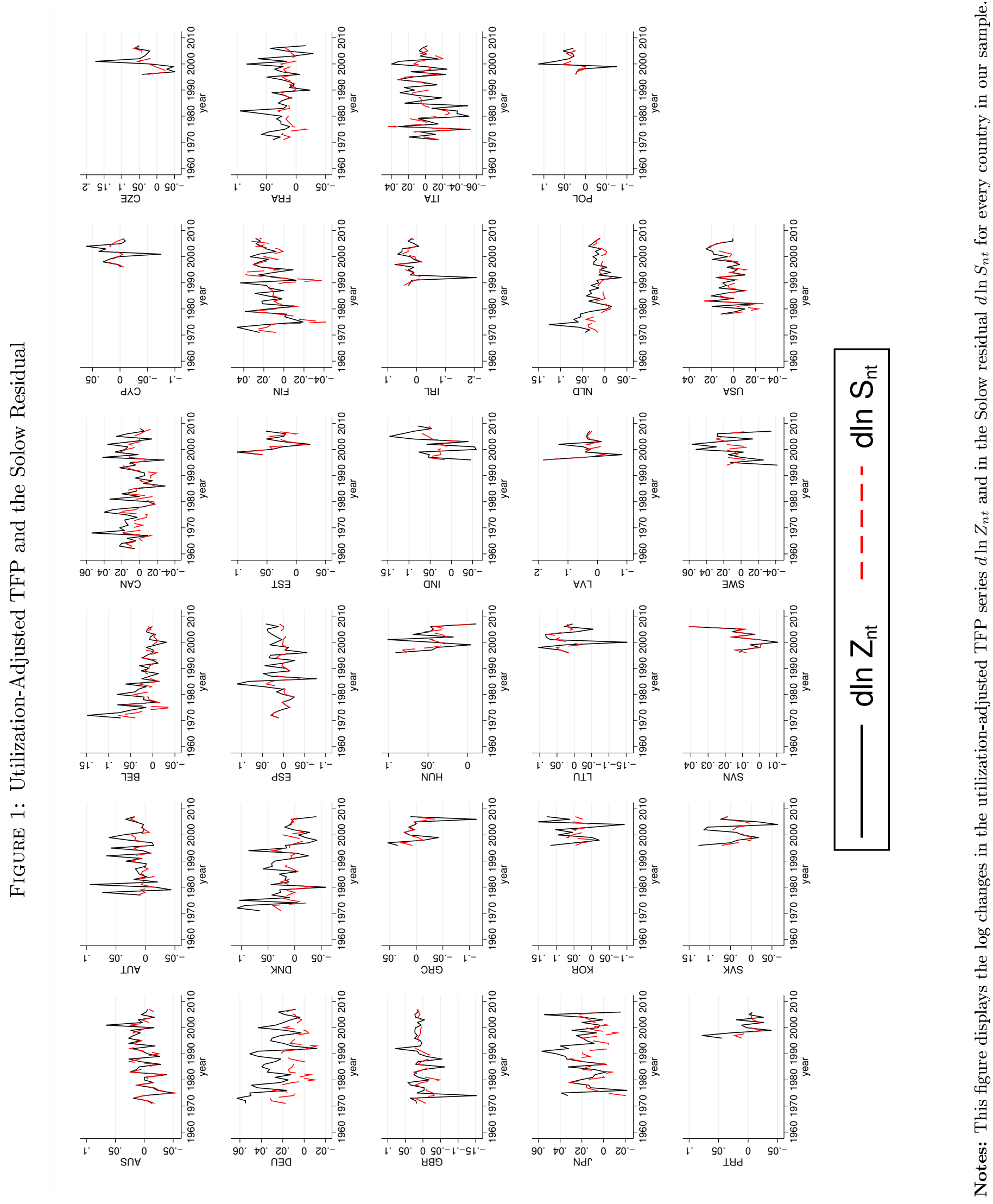


Sensitivity We construct a TFP series applying the original BFK production function coefficient estimates to all countries, and compare the resulting TFP series with ours. While our point estimates will naturally not coincide perfectly with those in BFK, they are not significantly different from the estimates in that paper in many cases. BFK Table 1 reports $\delta_{j}^{2}$ coefficients (s.e.'s) of 1.34(0.22), $2.13(0.38)$ and $0.64(0.34)$ for durables, non-durables and non-manufacturing respectively, not far from our estimates in Table 1. The correlation between our TFP series and the series constructed using BFK coefficients is 0.88 (Appendix Table A7).

Next, we repeat the TFP estimation procedure, but allowing sector-specific capital and value added shares $\alpha_{j}$ and $\eta_{j}$ to vary by country, and then by both country and year. The resulting series have correlations with the baseline of 0.97 and 0.96, as reported in Appendix Table A7.

One concern might be institutional differences in labor market flexibility across countries, such that hours per worker cannot adjust to the same extent in different countries. While our estimation approach does not treat all of the labor input as fully flexible, we do require that hours per worker respond within our annual time frame. To assuage this and other concerns about country heterogeneity, we estimate the coefficients excluding each of the G7 countries one by one, and construct TFP series with those alternative coefficients. Appendix Table A7 presents the pairwise correlations between our baseline TFP series, and all TFP series dropping an individual country. Excluding individual G7 countries from production function estimation leads to TFP series with correlations with our baseline between 0.94 and 1.00, suggesting our estimates are not driven by any country in particular. $^{8}$

We also estimate the production function using our full sample of 29 countries. The correlation of the resulting TFP series with the baseline is 0.83 . However, the estimated parameters are noisy and the first stage is not as strong, so we prefer our baseline estimates. The TFP series we construct for non-G7 countries thus use the G7 production function estimates. We advise caution when using those, as these production function parameters might be more appropriate for some non-G7 countries than others.

Our TFP estimation procedure also provides us with series for utilization rates by sector. In the US, the Federal Reserve Board (FRB) publishes a series of industry-level utilization. These series are constructed using a number of sources including survey data from the US Census Bureau, by dividing an index of industrial production by an index of estimated industrial capacity. The left

BFK is indeed that high true TFP tends to coincide with low utilization. While BFK emphasized the central role of this negative covariance for their results, for the US this negative covariance is not large enough to render the Solow residual less volatile than TFP. It turns out that in most other countries that is in fact the case.

${ }^{8}$ To assess whether there are clear first-order differences in the flexibility of hours per worker, we compute standard deviations of actual sectoral hours per worker growth rates. Reassuringly, the standard deviations of hours per worker are not systematically different between the countries with more flexible labor markets (US: 0.010; UK: 0.016; Canada: 0.014), and more inflexible ones (Germany: 0.015; France: 0.014; Italy: 0.014). 
panel of Appendix Figure A1 compares our industry-level estimates to these public series. The two are positively correlated, despite the different underlying data sources and methodologies used for constructing them. The right panel of the figure compares our estimates for the country-level average utilization growth rates against the country-level utilization based on the FRB data for the US, and Eurostat data for some European countries. Again, we find a positive and significant correlation, albeit somewhat low. ${ }^{9}$

International correlation decomposition To highlight the relative importance of TFP in international comovement, combine (2.3) and (3.9) to write real GDP growth as a sum of two components (see Appendix B.1 for the derivation):

$$
d \ln Y_{n t}=d \ln Z_{n t}+d \ln \mathcal{I}_{n t}
$$

where $d \ln \mathcal{I}_{n t}$ is the component of GDP growth accounted for by changes in inputs, and given by equation (B.4). Our estimation approach allows us to construct the true (utilization- and scaleadjusted) $d \ln \mathcal{I}_{n t}$.

Table 2 presents the basic summary statistics for the elements of the GDP decomposition (4.1). These results are useful for highlighting the role of the TFP shocks and comparing them to the Solow residual. The top panel reports the correlations among the G7 countries. The average correlation of real GDP growth among these countries is 0.36 . The second line summarizes correlations of the TFP shocks. Those are on average close to zero. By contrast, input growth is positively correlated, with a mean of 0.25 . The left panel of Figure 2 depicts the kernel densities of the correlations of real GDP, TFP, and inputs. There is a clear hierarchy, with the real GDP the most correlated, and the

\footnotetext{
${ }^{9}$ Both the US and the European data are available for the manufacturing sector only (the European survey has capacity utilization for services, but it starts in 2010, after the end of our sample in 2007). We stress that there is no strong reason to treat the capacity utilization surveys as closer to the truth than the BFK method. First, as a survey answer it entails some subjectivity. This is exacerbated by the fact that the question being asked differs somewhat between European countries, as detailed in Appendix A.2. By contrast, our measure of utilization intensity is just a transformation of log hours per worker. It has the benefit of being transparent and intuitive: workers working longer hours is a good indication of variable factors being used more intensively. It is concerning for the survey answers when the managers reporting low capacity utilization coincides with high hours per worker. Second, the survey question is about capacity utilization. Conceptually, the closest analog in our model to what the surveys are presumably capturing would be actual output divided by output when factors are utilized so intensively that the marginal costs of increasing utilization rise steeply. This is related, but not the same as our model's notion of variable factor utilization intensity. Third, the history of the development of capacity utilization series suggests caution in using the relatively new EU surveys as a benchmark. In the US, in response to concerns about earlier vintages of these data, the collection methodology was improved to provide managers with a detailed and precise notion of "full production capability," namely that the number of shifts, hours of operation and overtime pay can be sustained under normal conditions and a realistic work schedule in the long run. The EU surveys are more recent, and the mapping between them and theory is even less clear. As far as we are aware, the EU surveys do not provide managers with a precise notion of capacity. So each manager is more free to apply their own definition of "full capacity" output. Finally, one benefit of our approach is that we can produce measures of utilization-adjusted TFP for many more countries and sectors than capacity utilization surveys have available.
} 
TFP the least correlated and centered on zero.

Section 2 shows that the Solow residual can be written as a sum of the aggregate TFP growth and the aggregated variable utilization change $d \ln \mathcal{U}_{n t} \cdot{ }^{10}$ Thus, it is an empirical question to what degree correlations in the Solow residual reflect true technology shock correlation as opposed to endogenous input adjustments. Table 2 shows that the Solow residual has an average correlation of about 0.09 in the G7 countries. If Solow residuals were taken to be a measure of TFP shocks, we would have concluded that TFP is positively correlated in this set of countries. As we can see, this conclusion would be misleading. Indeed, the correlation in the utilization term $\mathcal{U}_{n t}$, which is the difference between the true TFP shock $d \ln Z_{n t}$ and the Solow residual, accounts for all of the correlation in the Solow residual, on average. This indicates that the correlation in the Solow residual is in fact driven by unobserved input utilization and scale adjustments. In our framework, sectoral unobserved utilization is a log-linear transformation of hours per worker. Table 2 shows that indeed the correlation in aggregated hours per worker $d \ln \mathcal{H}_{n t}$ accounts for the correlation in $d \ln \mathcal{U}_{n t}{ }^{11}$

The bottom panel of Table 2 repeats the exercise in the full sample of countries. The basic message is the same as for the G7. It is still the case that $d \ln Z_{n t}$ has a zero average correlation, whereas inputs $d \ln \mathcal{I}_{n t}$ are positively correlated and account on average for about half of the real GDP correlation. The Solow residuals are also more correlated than $d \ln Z_{n t}$, and the difference is accounted for by the fact that the unobserved inputs are positively correlated. The right panel of Figure 2 displays the kernel densities of the correlations in the full sample.

This is of course only an accounting decomposition. The growth in $\mathcal{I}_{n t}$ is endogenous to both TFP shocks at home and abroad, and to any non-TFP shocks. Though the TFP shocks themselves are uncorrelated, the induced endogenous GDP comovements may still be sizable when TFP shocks are transmitted across borders via production networks and goods trade. We next turn to a quantitative model of international shock propagation to assess the roles of TFP and variable utilization in international comovement.

\section{General Equilibrium}

This section implements the multi-sector IRBC model in Section 3. Appendix B presents a complete characterization of the equilibrium conditions. We proceed in two steps. First, when the adjustments of employment and machines are muted, the model can be viewed as an international version of the

\footnotetext{
${ }^{10}$ Now that we augmented the model with variable returns to scale, the difference between TFP and the Solow residual includes a scale adjustment, as in equation (B.6). In practice, the scale adjustment plays a minor role relative to unobserved utilization.

${ }^{11}$ The reasons the two do not coincide perfectly is scale effects and aggregation across sectors.
} 
TABle 2: Correlations Summary Statistics

\begin{tabular}{|c|c|c|c|c|}
\hline & Mean & Median & 25th pctile & 75th pctile \\
\hline & \multicolumn{4}{|c|}{ G7 Countries (N. obs. $=21)$} \\
\hline$d \ln Y_{n t}$ & 0.358 & 0.337 & 0.242 & 0.565 \\
\hline$d \ln Z_{n t}$ & 0.020 & -0.007 & -0.087 & 0.140 \\
\hline$d \ln \mathcal{I}_{n t}$ & 0.247 & 0.231 & 0.100 & 0.461 \\
\hline$d \ln S_{n t}$ & 0.086 & 0.120 & -0.022 & 0.300 \\
\hline$d \ln \mathcal{U}_{n t}$ & 0.152 & 0.157 & 0.082 & 0.301 \\
\hline \multirow[t]{2}{*}{$d \ln \mathcal{H}_{n t}$} & 0.175 & 0.223 & 0.073 & 0.314 \\
\hline & \multicolumn{4}{|c|}{ All countries $(\mathrm{N}$. obs. $=406)$} \\
\hline$d \ln Y_{n t}$ & 0.190 & 0.231 & -0.027 & 0.437 \\
\hline$d \ln Z_{n t}$ & -0.007 & 0.003 & -0.214 & 0.212 \\
\hline$d \ln \mathcal{I}_{n t}$ & 0.111 & 0.132 & -0.089 & 0.327 \\
\hline$d \ln S_{n t}$ & 0.052 & 0.083 & -0.150 & 0.296 \\
\hline$d \ln \mathcal{U}_{n t}$ & 0.047 & 0.076 & -0.172 & 0.262 \\
\hline$d \ln \mathcal{H}_{n t}$ & 0.054 & 0.083 & -0.132 & 0.261 \\
\hline
\end{tabular}

Notes: This table presents the summary statistics of the correlations in the sample of G7 countries (top panel) and full sample (bottom panel). Variable definitions and sources are described in detail in the text.

network propagation model following Acemoglu et al. (2012). This exercise emphasizes the role of the input-output linkages in amplifying or dampening the underlying contemporaneous sectoral shocks. The advantage of the network model is that it is transparent on the role of input linkages in shock propagation, and can be implemented on a large set of countries and a limited time series like we have in our data. The disadvantage is that it rules out dynamic responses of capital accumulation and intertemporal labor adjustment to the shocks. In the second step, we consider the G7 countries where a longer time series are available, and allow for dynamic responses to shocks, similar to our previous work (Huo, Levchenko, and Pandalai-Nayar, 2020). Both the static and dynamic versions of the model are solved by linearizing.

As stressed above, utilization can potentially contribute to international comovement for two distinct reasons: endogenous responses of utilization to TFP shocks, and shocks to utilization itself. To quantify both of these mechanisms, this section introduces a utilization shock that rationalizes the estimated variation in utilization and effort given the global vectors of TFP and predetermined employment and machines. We also subject the model to the standard Solow residual shocks to contrast them with TFP. 
FIguRE 2: Correlations: Kernel Densities
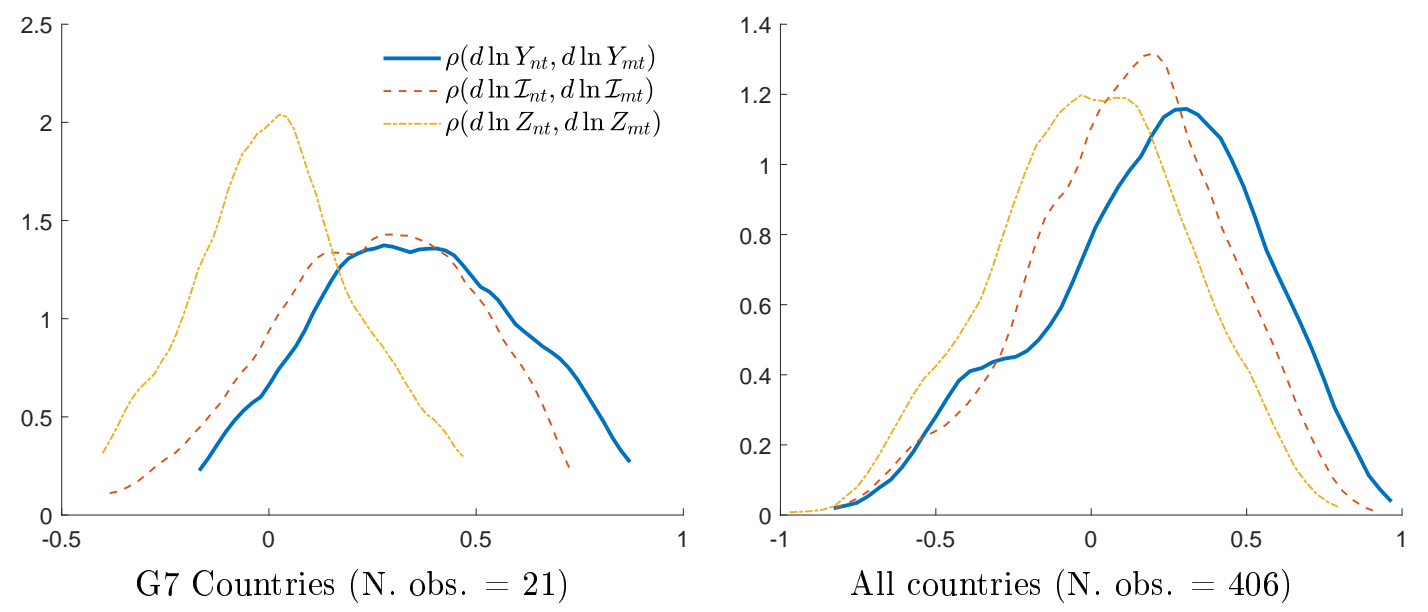

Notes: This figure displays the kernel densities of real GDP growth, the utilization-adjusted TFP, and input correlations in the sample of G7 countries (left panel) and full sample (right panel). Variable definitions and sources are described in detail in the text.

\subsection{Calibration}

Utilization shock The utilization shock is a shift in the supply of variable factors, $\xi_{n j t}$, in equation (3.1). Each period, given the observed true TFP and pre-determined machines and employment, we can compute the required utilization shock so that the model-implied unobserved inputs coincide with our estimated unobserved inputs. This shock is essentially the wedge between the estimated utilization and the one implied by the model with only TFP shocks. ${ }^{12}$ Unlike the TFP shocks, computing the utilization shock requires solving for the global equilibrium of the model, as the unobserved inputs are jointly determined in the world production network. Appendix B.4 describes the details of the procedure.

Elasticities In implementing the network model, we only need to take a stand on the value of a small number of parameters, and use our data to provide the required quantities. Table 3 summarizes the parameter assumptions for the network model and data sources. The exact functional forms of the final goods and intermediate goods Armington aggregators are given by equations (B.7) and (B.9) in Appendix B.2. In Huo, Levchenko, and Pandalai-Nayar (2020) we estimate the substitution elasticities in final and intermediate use. Based on these estimation results, the final goods (consumption and investment) Armington elasticity $\rho$ is set to 2.75, and the intermediate input substitution

\footnotetext{
${ }^{12}$ This wedge is different from the familiar labor wedge. Our model distinguishes hours from employment, and the utilization shocks help match the observed hours given the predetermined employment and machines. The utilization shock captures all margins of utilization - hours per worker, unobserved effort, and capital utilization rate.
} 
elasticity $\varepsilon$ is set to 1 . The scale parameters $\gamma_{j}$ come from our own production function estimates reported in Table 1. In practice, returns to scale are close to constant.

The remaining three parameters, $\psi_{j}^{h}, \psi_{j}^{e}$, and $\psi_{j}^{u}$, are elasticities of the supply of hours, effort, and capital utilization, respectively. We use a combination of empirical and theoretical restrictions to pin these down. Joint optimization of the different margins of utilization implies that to solve for equilibrium in this economy we do not need to know $\psi_{j}^{h}, \psi_{j}^{e}$, and $\psi_{j}^{u}$ individually. Rather, we only need a single composite utilization supply elasticity. To see this, combine the the optimality conditions for variable factors (B.10)-(B.11) with the production function to get:

$$
\begin{aligned}
d \ln Y_{n j t}= & d \ln Z_{n j t}+\widetilde{\psi}_{j} \gamma_{j} \eta_{j}\left(1-\alpha_{j}\right)\left(d \ln W_{n j t}+d \ln L_{n j t}-d \ln P_{n t}-d \ln \xi_{n j t}\right) \\
& +\gamma_{j}\left(1-\eta_{j}\right) d \ln X_{n j t}+\gamma_{j} \eta_{j}\left(\alpha_{j} d \ln M_{n j t}+\left(1-\alpha_{j}\right) d \ln N_{n j t}\right)
\end{aligned}
$$

where

$$
\widetilde{\psi}_{j} \equiv \frac{1}{\psi_{j}^{h}}+\frac{1}{\psi_{j}^{e}}+\frac{\alpha_{j}}{1-\alpha_{j}} \frac{1}{\psi_{j}^{u}}
$$

is the required composite elasticity.

Our production function estimates yield a restriction on these parameters. Equation (3.8) implies that the estimated $\zeta_{j}$ corresponds to $\alpha_{j} \frac{\psi_{j}^{h}}{\psi_{j}^{u}}+\left(1-\alpha_{j}\right) \frac{\psi_{j}^{h}}{\psi_{j}^{e}}$. Thus, $\widetilde{\psi}_{j}$ and $\zeta_{j}$ are related by:

$$
\widetilde{\psi}_{j}=\frac{1}{\psi_{j}^{h}}\left(1+\frac{\zeta_{j}}{1-\alpha_{j}}\right) .
$$

In the absence of effort and capital utilization margins, only the supply elasticity of hours $\psi_{j}^{h}$ is relevant. When variable effort and utilization are present, $\zeta_{j}$ and $\psi_{j}^{h}$ jointly govern the combined responsiveness of variable inputs, and our production function estimates put discipline on the value of $\zeta_{j}$.

The model structure also provides a bound on the choice of $\psi_{j}^{h}$. The steady-state employment level $N_{n j}$ must satisfy

$$
\frac{\psi^{n} N_{n j}^{\psi^{n}-1}}{\psi^{n} N_{n j}^{\psi^{n}-1}+G_{j}\left(H_{n j}, E_{n j}, U_{n j}\right)}=1-\widetilde{\psi}_{j} .
$$

The constraint that employment must be positive thus imposes a restriction that the composite factor supply elasticity $\widetilde{\psi}_{j}$ is less than one. When effort and capital utilization adjustments are muted, this simply amounts to the restriction that the Frisch labor supply elasticity $\left(\psi_{j}^{h}-1\right)^{-1}$ is positive. Given the discussion above, in the baseline parameterization we set the composite elasticity $\widetilde{\psi}_{j}$ to be 0.5 in all sectors, which corresponds to a Frisch elasticity equal to one in the absence of effort and utilization variation. Given our estimates of $\zeta_{j}$, the sector-specific $\psi_{j}^{h}$ can be obtained accordingly. Appendix 
TABLE 3: Parameter Values

\begin{tabular}{lcll}
\hline Param. & Value & Source & Related to \\
\hline$\rho$ & 2.75 & Huo, Levchenko, and Pandalai-Nayar (2020) & final substitution elasticity \\
$\varepsilon$ & 1 & Huo, Levchenko, and Pandalai-Nayar (2020) & intermediate substitution elasticity \\
$\gamma_{j}$ & & Table 1 & returns to scale \\
$\zeta_{j}$ & & Table 1 & joint restriction on variable input elasticities \\
$\widetilde{\psi}_{j}$ & 0.5 & See Section 5.1 & composite variable input elasticity \\
$\alpha_{j}, \eta_{j}$ & & KLEMS & capital shares, intermediate shares \\
$\pi_{m n j t}^{f}$ & & WIOD & final use trade shares \\
$\pi_{m i, n j t}^{x}$ & & WIOD & intermediate use trade shares \\
$\omega_{n j}$ & WIOD & final consumption shares \\
\hline
\end{tabular}

Notes: This table summarizes the parameters and data targets used in the quantitative model, and their sources.

B.5 assesses sensitivity to alternative elasticities. The main quantitative implications remain valid under the alternative parameterizations.

Shares All other parameters in the model have close counterparts in basic data and thus we compute them directly. The ratio of value added to gross output corresponds to $\eta_{j}$. The labor share $\left(1-\alpha_{j}\right)$ is computed as labor payments as a fraction of value added. In KLEMS, payments to capital are computed as the difference between measured sectoral value added and payments to labor. This implies that profits are mechanically included in the capital share. Both $\eta_{j}$ and $\left(1-\alpha_{j}\right)$ come from KLEMS (see Appendix Table A3), and are averaged in each sector across countries and years in the baseline calibration to minimize noise. As noted above, allowing these parameters to be country-sector-time specific leads to very similar TFP series. Steady state input shares $\left(\pi_{m i, n j}^{x}\right)$ and final consumption shares $\left(\pi_{m n j}^{f}\right)$ are computed from WIOD as time averages.

\subsection{Model GDP Correlations}

Table 4 reports GDP correlations in our model with employment and capital being fixed. The model is simulated with the utilization-adjusted TFP shocks, the utilization shocks, and the Solow residuals. As our model can only be implemented on a balanced panel, we report results both for a longer G7-only version of the model spanning years 1978-2007, as well as an all-countries version spanning 1995-2007- the longest timespan for which data are available for all 29 countries. For the G7 group, TFP shocks generate mean GDP correlations of 0.03, less than one-tenth of the level found in the data. For the full sample of countries, TFP shocks produce mean correlations of 
essentially zero. When TFP shocks are uncorrelated, the model can still exhibit GDP comovement through endogenous propagation of shocks. This propagation would manifest itself as comovements in variable factors of production - hours, effort, and capital utilization. The fact that GDP is at best only weakly correlated when the model is subjected to the TFP shocks suggests that endogenous responses of utilization to TFP shocks do very little to synchronize GDP.

The rows labeled "Model, utilization shock" of Table 4 report GDP correlations under the utilization shock. As primary inputs are more correlated than TFP and the utilization shock rationalizes variable inputs that are tied to hours per worker, it is not surprising that the utilization shock generates significantly higher GDP comovement. The utilization shock alone generates between onequarter and one-third of the observed GDP correlations in the two samples of countries. The model with both TFP and utilization shocks generates about half of the observed correlations in the data.

Section 4 highlighted that the Solow residual is more correlated than true TFP, and that its properties are quite different from true TFP. We now explore the implications of feeding in the Solow residual as a measure of technology shocks into our model where factor utilization can vary. This exercise helps assess the consequences of mismeasurement: if the true model features unobserved factor utilization, and the Solow residual is mistakenly used as the measure of technology innovations, what would we conclude about the contribution of technology shocks for comovement? The rows labeled "model, Solow residual" of Table 4 report GDP comovement with the Solow residual as the shock. For both country samples, comovement is higher with the Solow residual than true TFP. Solow residuals can generate about $25 \%$ of the level of observed GDP correlations. These results suggest that TFP mismeasurement does affect our understanding of the role of technology shocks in international comovement.

Now we turn to the dynamic model where employment and capital are endogenously determined every period. To solve the dynamic model, it is necessary to estimate the shock processes for agents to forecast future aggregate outcomes. We impose a parsimonious structure by allowing the sectorspecific TFP and utilization shocks to follow autoregressive processes that depend on their own past values and past values of other sectors within the same country. ${ }^{13}$ This estimation can only be conducted for G7 countries where a relatively long panel is available. Additional parameters that are only relevant in the dynamic model are specified as follows. We choose the utility function $\Psi(\cdot)=\log (\cdot)$. The depreciation rates $\varrho_{j}$ are set to match the sector specific depreciation rates obtained from the BEA in 2001. The less standard parameter is $\psi^{n}$ which controls the employment adjustment costs. In the baseline, we set $\psi^{n}$ to be 4 and we vary it in Appendix B.5. As can be seen in Table 5, adding dynamics in capital and employment does not significantly modify the overall pattern of GDP comovement. This is mainly due to the fact that GDP growth rates are determined

\footnotetext{
${ }^{13}$ See Appendix B.4 for more details on the shock processes.
} 
for the most part by the the impact responses, which are already captured in the static model.

TABLE 4: GDP Correlations in the Data and in the Static Model

\begin{tabular}{lcccc}
\hline & Mean & Median & 25th pctile & 75th pctile \\
\hline & \multicolumn{5}{c}{ G-7 countries (N. obs. = 21) } \\
Data & 0.358 & 0.337 & 0.242 & 0.565 \\
Model, TFP shock & 0.030 & 0.015 & -0.100 & 0.153 \\
Model, utilization shock & 0.126 & 0.124 & 0.008 & 0.1853 \\
Model, TFP and utilization shocks & 0.197 & 0.244 & -0.020 & 0.401 \\
Model, Solow residual & 0.086 & 0.103 & -0.084 & 0.332 \\
\hline & & All countries (N. obs. $=406)$ \\
Data & 0.190 & 0.231 & -0.027 & 0.437 \\
Model, TFP shock & 0.005 & -0.011 & -0.201 & 0.230 \\
Model, utilization shock & 0.046 & 0.057 & -0.168 & 0.277 \\
Model, TFP and utilization shocks & 0.096 & 0.090 & -0.151 & 0.380 \\
Model, Solow residual & 0.051 & 0.032 & -0.200 & 0.313 \\
\hline
\end{tabular}

Notes: This table presents the summary statistics of the correlations of $d \ln Y_{n t}$ in the sample of G7 countries for 1978-2007 (top panel) and full sample for 19952007 (bottom panel) in the data and the model with various shocks. Variable definitions and sources are described in detail in the text.

TABle 5: GDP Correlations in the Data and in the Dynamic Model

\begin{tabular}{lcccc}
\hline & Mean & Median & 25th pctile & 75th pctile \\
\hline & \multicolumn{5}{c}{ G-7 countries (N. obs. = 21) } \\
Data & 0.358 & 0.337 & 0.242 & 0.565 \\
Model, TFP shock & 0.002 & -0.005 & -0.175 & 0.178 \\
Model, utilization shock & 0.132 & 0.099 & -0.010 & 0.218 \\
Model, TFP and utilization shocks & 0.264 & 0.305 & 0.051 & 0.484 \\
Model, Solow residual & 0.065 & 0.081 & -0.128 & 0.285 \\
\hline
\end{tabular}

Notes: This table presents the summary statistics of the correlations of $d \ln Y_{n t}$ in the sample of G7 countries for 1978-2007 and the model with various shocks. 
Sensitivity Appendix Tables A9-A10 present the model correlations under a variety of parameter combinations in the static and dynamic cases, respectively. Lower substitution elasticities $\rho$ and $\varepsilon$, or more elastic factor supply (higher $\widetilde{\psi}_{j}$ ) have the expected effect of greater GDP synchronization. The "max transmission" model that combines lower $\rho$ and $\varepsilon$ with higher $\widetilde{\psi}_{j}$ generates TFP-driven average GDP correlations of 0.078 and 0.036 in the G7 countries and the full sample, respectively. While this is considerably higher than the baseline (0.03 and 0.005), it is still well short of observed comovement. The bottom panel reports the results of a model that suppresses the input network and leaves only final goods trade. The resulting correlations are lower than the baseline, but not dramatically so. This is consistent with the notion that international transmission forces, while present, are not predominant in this framework.

\section{Conclusion}

When some margins of factor utilization are unobservable, the Solow residual is a misleading measure of technology innovations. While use of utilization-adjusted TFP is common in the research on the US economy, international macroeconomics has thus far worked with the Solow residual. This paper makes two contributions. First, we provide a new dataset containing utilization-adjusted TFP series for many countries and sectors for use in open-economy macroeconomics. We illustrate that these series have different international correlation properties from the standard Solow residual. Second, we quantify the roles of TFP and variable factor utilization in international comovement. We find that while TFP shocks do not generate substantial correlation in GDP growth rates across countries, shocks to variable utilization are more correlated and thus carry greater potential to synchronize GDP. Future research should focus on non-technology shocks as drivers of international business cycles. 


\section{References}

Acemoglu, Daron, Ufuk Akcigit, and William Kerr. 2016. "Networks and the Macroeconomy: An Empirical Exploration." NBER Macroeconomics Annual 2015 30:276-335.

Acemoglu, Daron, Vasco M. Carvalho, Asuman Ozdaglar, and Alireza Tahbaz-Salehi. 2012. "The Network Origins of Aggregate Fluctuations." Econometrica 80 (5):1977-2016.

Ambler, Steve, Emanuela Cardia, and Christian Zimmermann. 2004. "International business cycles: What are the facts?" Journal of Monetary Economics 51 (2):257-276.

Backus, David K, Patrick J Kehoe, and Finn E Kydland. 1992. "International Real Business Cycles." Journal of Political Economy 100 (4):745-75.

Basu, Susanto, John G. Fernald, and Miles S. Kimball. 2006. "Are Technology Improvements Contractionary?" American Economic Review 96 (5):1418-1448.

Bils, Mark and Jang-Ok Cho. 1994. "Cyclical factor utilization." Journal of Monetary Economics $33(2): 319-354$.

Boehm, Christoph and Nitya Pandalai-Nayar. 2019. "Convex Supply Curves." Mimeo, UT Austin.

Burnside, Craig, Martin Eichenbaum, and Sergio Rebelo. 1993. "Labor Hoarding and the Business Cycle." Journal of Political Economy 101 (2):245-273.

_ 1995. "Capital Utilization and Returns to Scale." In NBER Macroeconomics Annual, vol. 10. MIT Press, 67-124.

Canova, Fabio. 2005. "The transmission of US shocks to Latin America." Journal of Applied Econometrics 20 (2):229-251.

Chodorow-Reich, Gabriel, Loukas Karabarbounis, and Rohan Kekre. 2019. "The Macroeconomics of the Greek Depression." Mimeo, Harvard, Minnesota, and Chicago Booth.

Christiano, Lawrence J., Roberto Motto, and Massimo Rostagno. 2014. "Risk Shocks." American Economic Review 104 (1):27-65.

Cooley, Thomas F, Gary D Hansen, and Edward C Prescott. 1995. "Equilibrium Business Cycles with Idle Resources and Variable Capacity Utilization." Economic Theory 6 (1):3549. 
Corsetti, Giancarlo, Luca Dedola, and Sylvain Leduc. 2014. "The International Dimension of Productivity and Demand Shocks in the US Economy." Journal of the European Economic Association 12 (1):153-176.

Fair, Ray. 2018. "Macroeconometric modeling: 2018." Mimeo, Yale.

Fernald, John. 2014. "A Quarterly, Utilization-Adjusted Series on Total Factor Productivity." Federal Reserve Bank of San Francisco Working Paper 2012-19.

Gilchrist, Simon and John C. Williams. 2000. "Putty-Clay and Investment: A Business Cycle Analysis." Journal of Political Economy 108 (5):928-960.

Gorodnichenko, Yuriy and Matthew Shapiro. 2011. "Using the Survey of Plant Capacity to Measure Capital Utilization." Working Papers 11-19, Center for Economic Studies, U.S. Census Bureau.

Greenwood, Jeremy, Zvi Hercowitz, and Gregory W Huffman. 1988. "Investment, Capacity Utilization, and the Real Business Cycle." American Economic Review 78 (3):402-17.

Hamilton, James D. 1996. "This is what happened to the oil price-macroeconomy relationship." Journal of Monetary Economics 38 (2):215-220.

Heathcote, Jonathan and Fabrizio Perri. 2002. "Financial autarky and international business cycles." Journal of Monetary Economics 49 (3):601-627.

Huo, Zhen, Andrei A. Levchenko, and Nitya Pandalai-Nayar. 2020. "International Comovement in the Global Production Network." NBER Working Paper 25978.

Imbs, Jean. 1999. "Technology, growth and the business cycle." Journal of Monetary Economics $44(1): 65-80$.

Kose, M. Ayhan, Christopher Otrok, and Charles H. Whiteman. 2003. "International Business Cycles: World, Region, and Country-Specific Factors." American Economic Review 93 (4):1216-1239.

Levchenko, Andrei A. and Nitya Pandalai-Nayar. 2020. "TFP, News, and "Sentiments": The International Transmission of Business Cycles." Journal of the European Economic Association 18 (1):302-341.

O’Mahony, Mary and Marcel P. Timmer. 2009. "Output, Input and Productivity Measures at the Industry Level: The EU KLEMS Database." The Economic Journal 119 (538):F374F403. 
Shapiro, Matthew D. 1989. "Assessing the Federal Reserve's Measures of Capacity Utilization." Brookings Paper on Economic Activity (1):181-241.

- 1993. "Cyclical Productivity and the Workweek of Capital." American Economic Review 83 (2):229-233.

Timmer, Marcel P., Erik Dietzenbacher, Bart Los, Robert Stehrer, and Gaaitzen J. de Vries. 2015. "An Illustrated User Guide to the World Input-Output Database: the Case of Global Automotive Production." Review of International Economics 23 (3):575-605. 


\section{ONLINE APPENDIX}

\section{A Data and Estimation}

A.1 Data Sample and Variable Construction Details

TABle A1: Country Sample

\begin{tabular}{lll}
\hline Australia & Germany & Netherlands \\
Austria & Greece & Poland \\
Belgium & Hungary & Portugal \\
Canada & India & Slovak Republic \\
Cyprus & Ireland & Slovenia \\
Czech Republic & Italy & Spain \\
Denmark & Japan & Sweden \\
Estonia & Republic of Korea & UK \\
Finland & Latvia & USA \\
France & Lithuania & \\
\hline
\end{tabular}




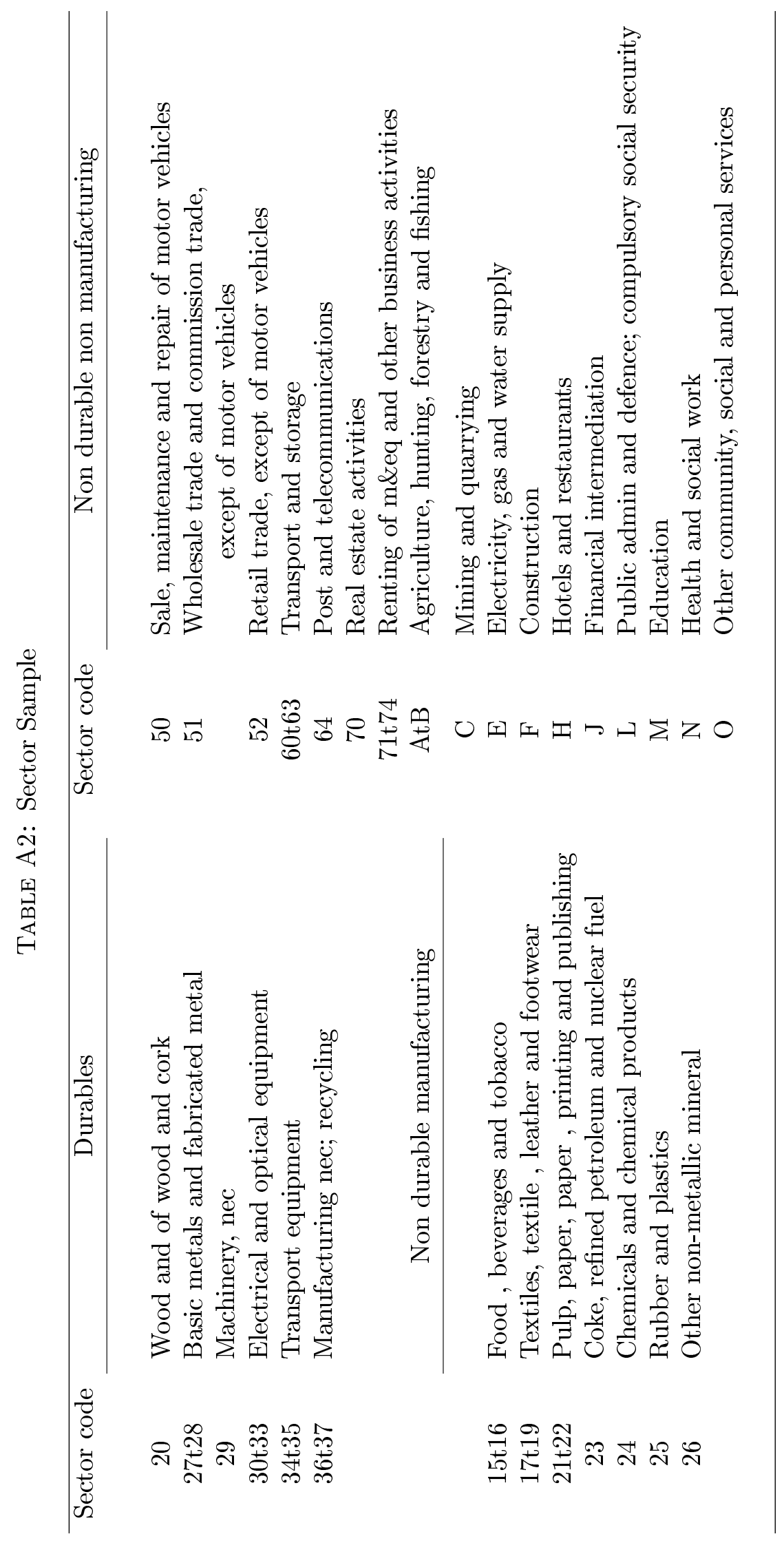


TABle A3: Data Construction Details

\begin{tabular}{|c|c|c|c|}
\hline Object & $\begin{array}{l}\text { KLEMS } \\
\text { variables }\end{array}$ & Construction & $\begin{array}{c}\text { WIOD SEA } \\
\text { supplementary variables }\end{array}$ \\
\hline$d \ln Y_{n j t}$ & $\begin{array}{l}\mathrm{GO} \\
\mathrm{GO}{ }_{-} \mathrm{P}\end{array}$ & $\begin{array}{l}d \ln Y_{n j t}=d \ln \mathrm{GO}- \\
d \ln \mathrm{GO}_{-} \mathrm{P}\end{array}$ & \\
\hline$d \ln M_{n j t}$ & $\mathrm{CAP}_{-} \mathrm{QI}$ & $d \ln M_{n j t}=d \ln \mathrm{CAP}_{-} \mathrm{QI}$ & $\begin{array}{l}\text { K_GFCF for the following coun- } \\
\text { tries: EST, CYP, GRC, KOR, LTU, } \\
\text { LVA, POL, PRT, SVK, SVN } \\
\text { When necessary, the lower aggrega- } \\
\text { tion of WIOD is aggregated up to } \\
\text { our sectoral classification by using } \\
\text { a weighted average of growth rates, } \\
\text { using } \frac{\mathrm{CAP}_{t}+\mathrm{CAP} \mathrm{P}_{t-1}}{2} \text { as weights. }\end{array}$ \\
\hline$d \ln H_{n j t}$ & $\begin{array}{l}\mathrm{H} \_ \text {EMP } \\
\text { EMP, } \\
\text { LAB_QI }\end{array}$ & $\begin{array}{l}d \ln H_{n j t}=d \ln \mathrm{H}_{-} \mathrm{EMP}- \\
d \ln \mathrm{EMP}\end{array}$ & $\begin{array}{l}\text { H_EMP for IND, and some sec- } \\
\text { tors in JPN and LTU. For AUS } \\
\text { and SVK, when H_EMP is miss- } \\
\text { ing from both KLEMS and WIOD, } \\
\text { we use } d \ln \text { LAB_QI instead of } \\
d \ln \mathrm{H}_{-} \text {EMP }\end{array}$ \\
\hline$d \ln N_{n j t}$ & EMP & $d \ln N_{n j t}=d \ln \mathrm{EMP}$ & $\begin{array}{l}\text { EMP for IND, and some sectors in } \\
\text { JPN and LTU }\end{array}$ \\
\hline$d \ln X_{n j t}$ & II, II_P & $d \ln X_{n j t}=d \ln \mathrm{II}-d \ln \mathrm{II}_{-} \mathrm{P}$ & \\
\hline$\alpha_{j}$ & $\mathrm{CAP}, \mathrm{GO}$ & $\begin{array}{l}\alpha_{n j t}=\frac{\mathrm{CAP}_{n j t}}{\mathrm{GO}_{n j t}} . \text { We take the } \\
\text { average } \alpha_{j} \text { over countries and } \\
\text { time }\end{array}$ & \\
\hline$\eta_{j}$ & $\begin{array}{l}\text { LAB, } \\
\text { CAP, GO }\end{array}$ & $\begin{array}{l}\eta_{n j t}=1-\frac{\mathrm{CAP}_{n j t}}{\mathrm{GO}_{n j t}}-\frac{\mathrm{LAB}_{n j t}}{\mathrm{GO}_{n j t}} \\
\text { We take the average } \eta_{j} \text { over } \\
\text { countries and time }\end{array}$ & \\
\hline
\end{tabular}




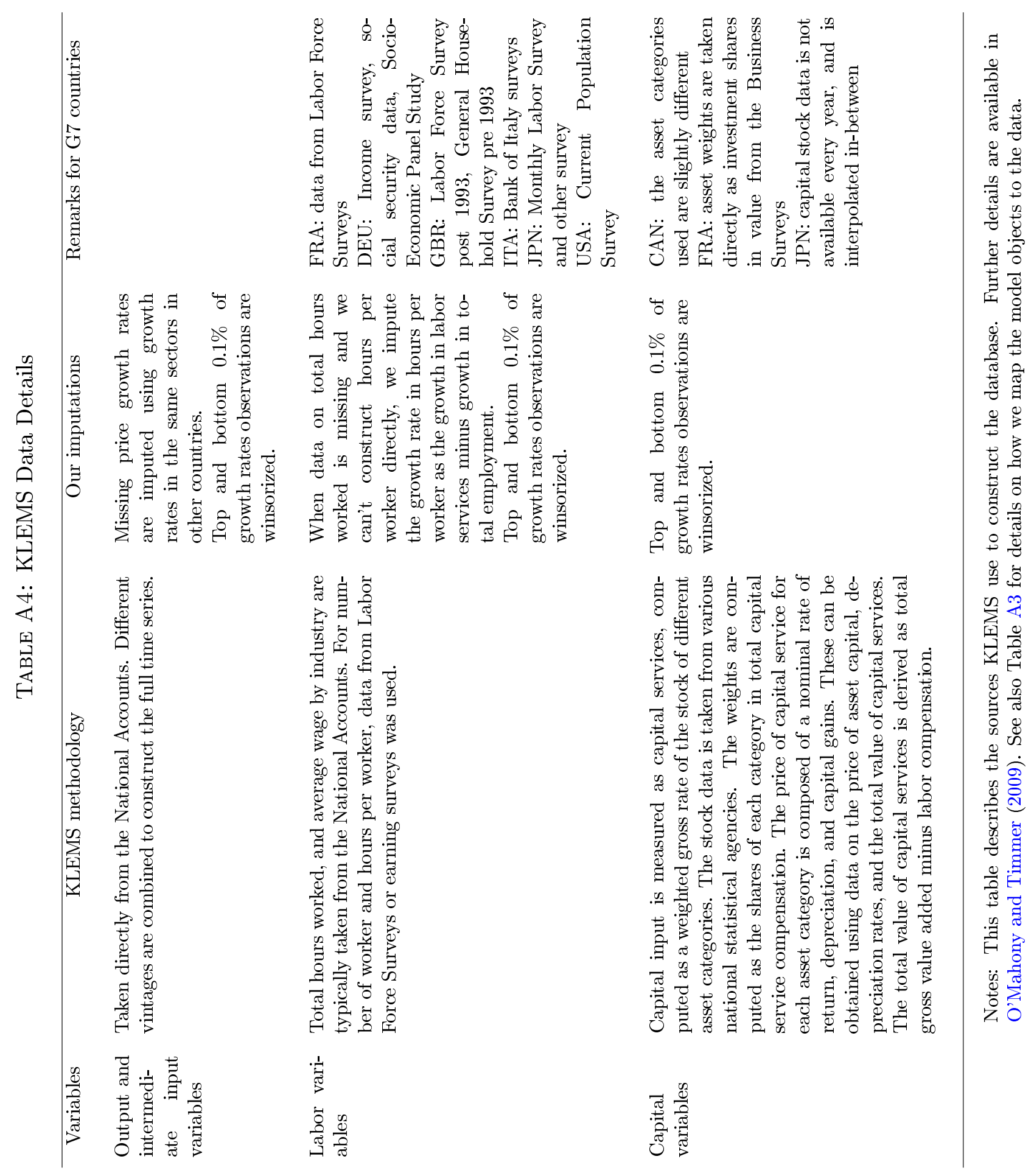




\section{A.2 Robustness of Estimates}

Robustness of our production function estimates Table A5 provides coefficient estimates under alternative combinations of instruments. Table A6 allows for sectoral returnsto-scale coefficients. For this estimation, we interact the direct exposure instruments with sector indicators. In many cases, the returns-to-scale coefficients are not significantly different from the baseline group-level estimate. However, the estimates are noisy, and the utilization adjustment coefficient is also estimated with more noise.

Robustness of TFP series Table A7 correlates our baseline TFP series with several alternatives based on BFK coefficients, estimation using the full 29-country sample, estimation excluding one G7 country at a time, estimation using country-sector specific or country-sectortime varying labor and input shares. The resultant TFP series are highly correlated with our baseline series.

Comparison to capacity utilization surveys Figure A1 compares our implied utilization series to survey data on utilization growth rates and finds a modest positive correlation. We advise caution in interpreting these results, particularly the right panel that compares our series to Eurostat survey measures. The precise question in the survey varies somewhat from country to country, and does not define full capacity for the managers filling out the survey, which might lead to some subjectivity in the responses and reduce their cross-country comparability. For instance, for the UK, the question we use is "What is your current rate of operation as a percentage of full capacity?" (Question 4a). For France, the question is "Votre entreprise fonctionne actuellement à ...\% de ses capacités disponibles. Il s'agit du ratio (en \%) de votre production actuelle sur la production maximale que vous pourriez obtenir en embauchant éventuellement du personnel supplémentaire" (Question 2c). This translates to "Your firm is currently operating at ... \% of its full capacity. It means the ratio (in \%) of your current production over the maximum production you could reach, potentially by hiring additional staff." Clearly, the question for France provides a notion of capacity that includes additional employment, unlike the question in the UK. In contrast, the question for Germany (Question B) suggests a capital-based capacity definition, "Die Ausnutzung unserer Anlagen zur Herstellung von XY (betriebsübliche Vollausnutzung=100\%) beträgt gegenwärtig bis ...\%", which translates to "The utilization of our installations for the production of XY (normal full utilization $=100 \%$ ) is currently up to ...\%." 


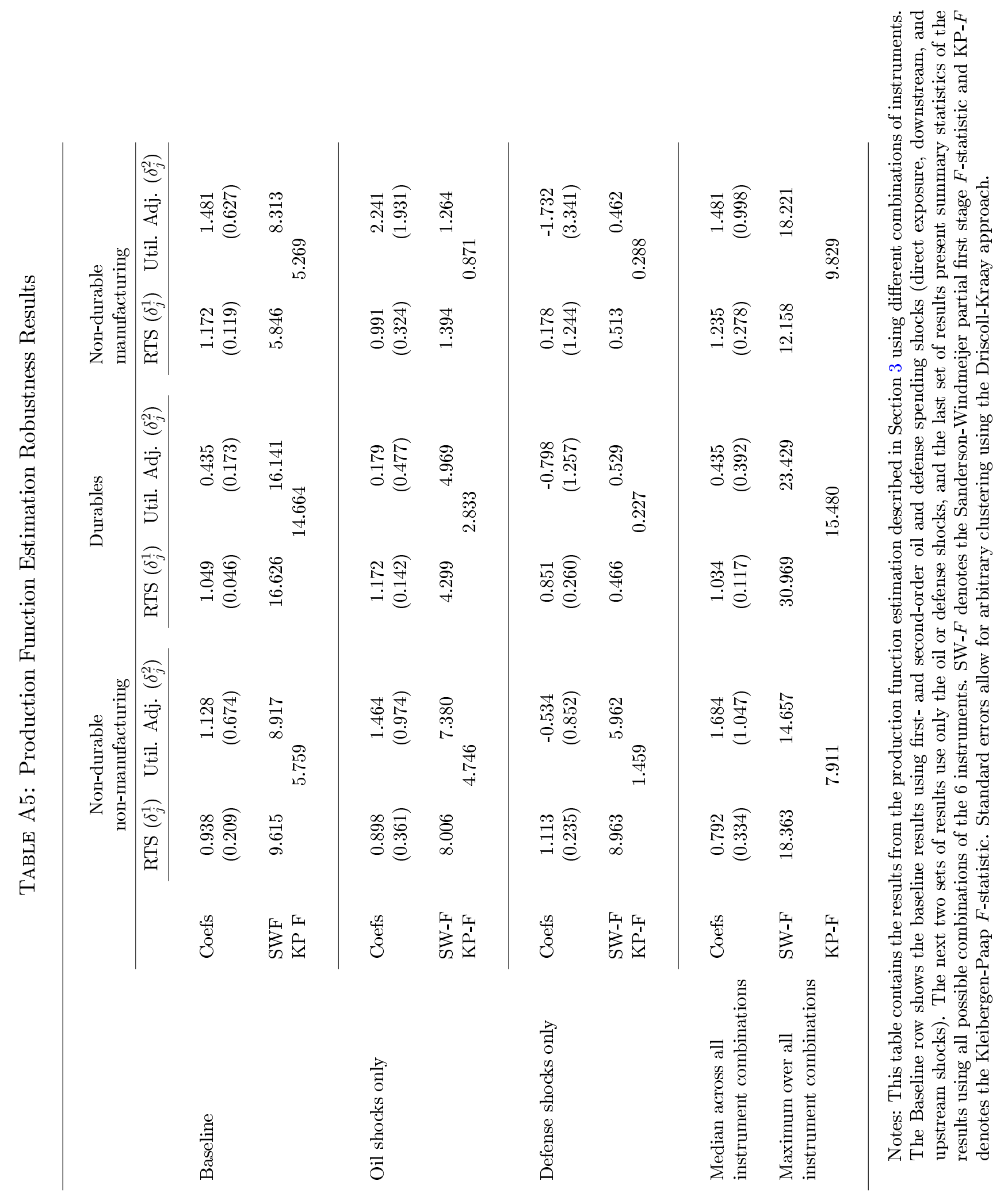


TABle A6: Sector-Specific RTS Production Function Estimation

\begin{tabular}{|c|c|c|c|c|c|}
\hline \multicolumn{3}{|c|}{ Durables } & \multicolumn{3}{|c|}{ Non-durable non-manufacturing } \\
\hline Sector & $\operatorname{RTS}\left(\delta_{j}^{1}\right)$ & Util. Adj. $\left(\delta_{j}^{2}\right)$ & Sector & $\operatorname{RTS}\left(\delta_{j}^{1}\right)$ & Util. Adj. $\left(\delta_{j}^{2}\right)$ \\
\hline 20 & $\begin{array}{c}0.946 \\
(0.094)\end{array}$ & & 50 & $\begin{array}{c}1.586 \\
(0.695)\end{array}$ & \\
\hline $27 \mathrm{t} 28$ & $\begin{array}{c}1.257 \\
(0.136)\end{array}$ & 0.373 & 51 & $\begin{array}{c}1.974 \\
(0.663)\end{array}$ & -0.552 \\
\hline 29 & $\begin{array}{l}1.403 \\
(0.19)\end{array}$ & $(0.175)$ & 52 & $\begin{array}{c}0.436 \\
(1.097)\end{array}$ & $(0.652)$ \\
\hline $30 \mathrm{t} 33$ & $\begin{array}{c}0.773 \\
(0.277)\end{array}$ & & $60 \mathrm{t} 63$ & $\begin{array}{c}1.346 \\
(0.154)\end{array}$ & \\
\hline $34 \mathrm{t} 35$ & $\begin{array}{c}1.198 \\
(0.101)\end{array}$ & & 64 & $\begin{array}{c}0.225 \\
(0.815)\end{array}$ & \\
\hline $36 \mathrm{t} 37$ & $\begin{array}{l}1.008 \\
(0.13)\end{array}$ & & 70 & $\begin{array}{l}-0.078 \\
(0.451)\end{array}$ & \\
\hline Nor & durable $\mathrm{m}$ & nufacturing & $71 \mathrm{t} 74$ & $\begin{array}{c}0.956 \\
(0.28)\end{array}$ & \\
\hline Sector & RTS & Util. Adj. & AtB & $\begin{array}{c}1.414 \\
(0.284)\end{array}$ & \\
\hline $15 \mathrm{t} 16$ & 0.803 & & $\mathrm{C}$ & $\begin{array}{l}-0.049 \\
(0.368)\end{array}$ & \\
\hline & $(0.457)$ & & $\mathrm{E}$ & 2.441 & \\
\hline $17 \mathrm{t} 19$ & $\begin{array}{c}0.995 \\
(0.173)\end{array}$ & 1.161 & $\mathrm{~F}$ & $\begin{array}{c}(1.102) \\
0.917\end{array}$ & \\
\hline $21 \mathrm{t} 22$ & $\begin{array}{c}0.894 \\
(0.207)\end{array}$ & $(0.596)$ & $\mathrm{H}$ & $\begin{array}{c}(0.356) \\
1.531\end{array}$ & \\
\hline 23 & $\begin{array}{c}1.183 \\
(0.144)\end{array}$ & & $\mathrm{J}$ & $\begin{array}{c}(0.478) \\
0.883\end{array}$ & \\
\hline 24 & $\begin{array}{l}1.276 \\
(0.08)\end{array}$ & & L & $\begin{array}{c}(0.461) \\
1.763\end{array}$ & \\
\hline 25 & $\begin{array}{l}(0.08) \\
1.313\end{array}$ & & $\mathrm{~L}$ & $\begin{array}{l}1.763 \\
(0.892)\end{array}$ & \\
\hline & $(0.085)$ & & $\mathrm{M}$ & 0.701 & \\
\hline 26 & $\begin{array}{c}1.226 \\
(0.207)\end{array}$ & & $\mathrm{N}$ & $\begin{array}{c}(0.242) \\
2.423 \\
(2.137)\end{array}$ & \\
\hline & & & $\mathrm{O}$ & $\begin{array}{c}1.082 \\
(0.227)\end{array}$ & \\
\hline
\end{tabular}

Notes: This table contains the results from the production function estimation described in Section 3, but allowing for sector-specific RTS coefficients. The direct exposure instruments are interacted with sector indicators in the first stage. Standard errors allow for arbitrary clustering using the Driscoll-Kraay approach. 


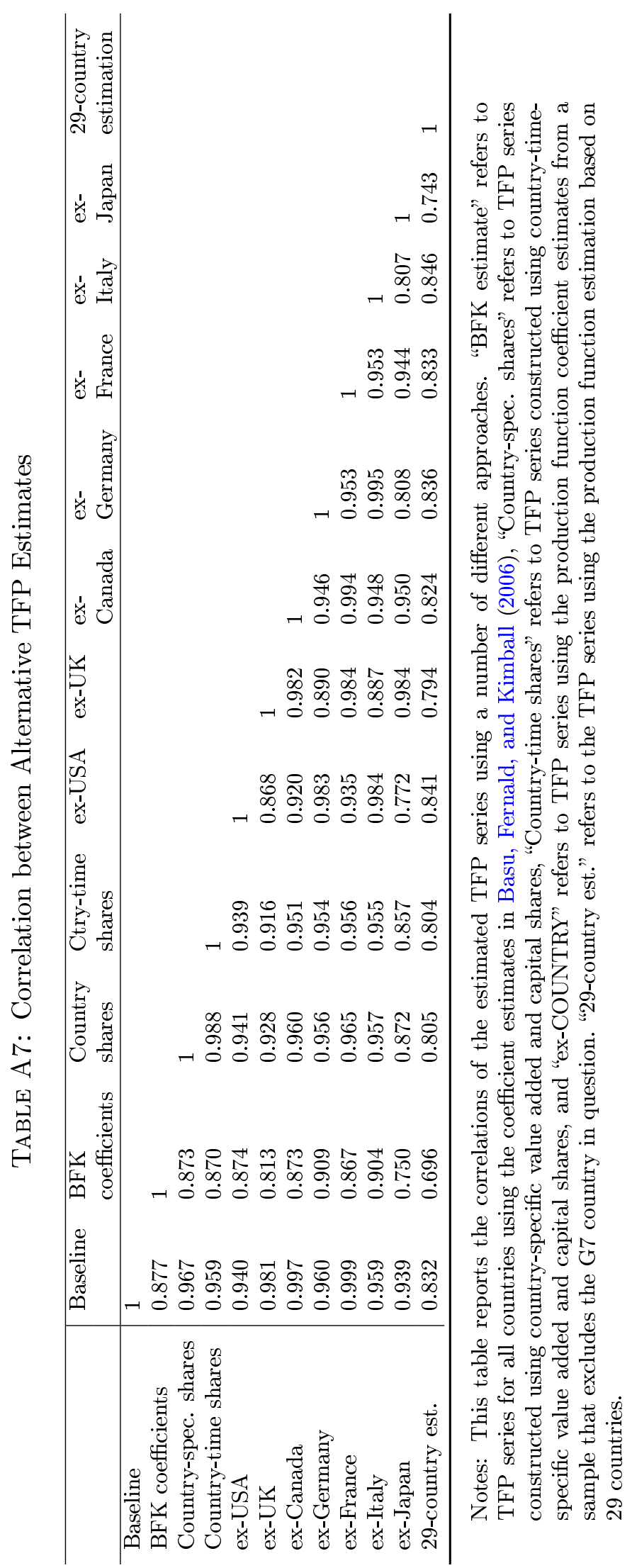


Figure A1: Comparison between Estimated Utilization and Survey Data

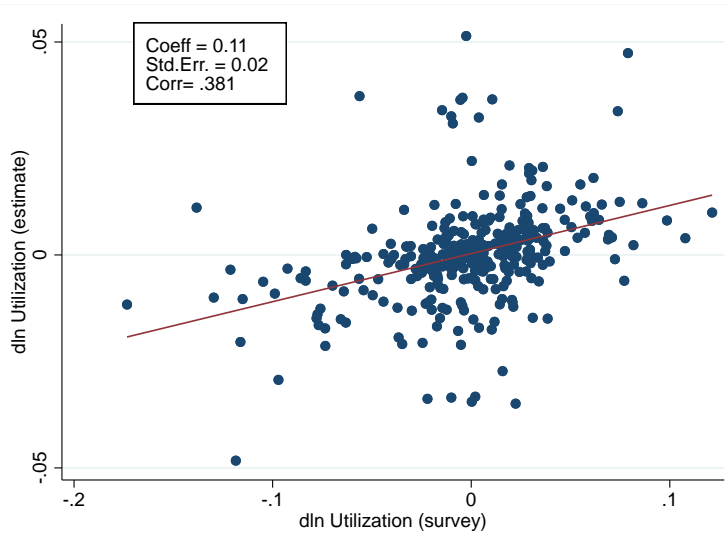

US sectoral data

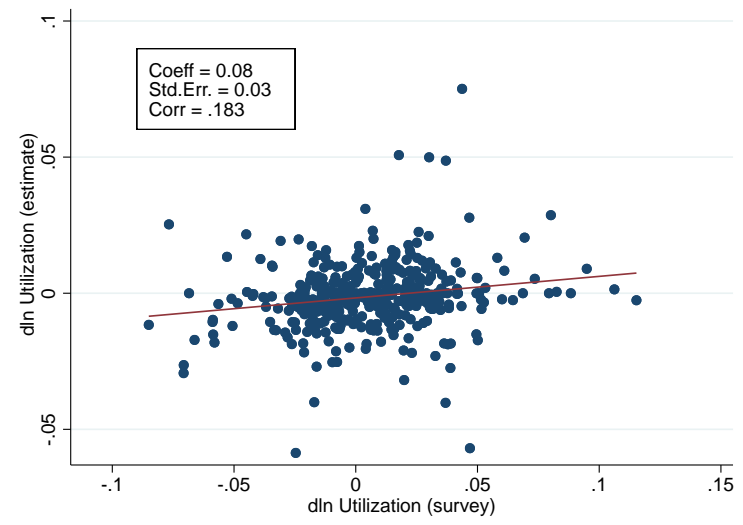

Country average

Notes: This figure compares our estimated utilization growth rate and the change in survey measures of capacity utilization. The left panel plots growth rates of the sector-level utilization series for the US based on our procedure against the FRB utilization survey. The right panel plots the growth rate of the country-level average utilization rate based on our procedure against utilization growth rates based on surveys by the FRB for the US and Eurostat for European countries (we use the answer to the question in the UK survey At what capacity is your company currently operating (as a percentage of full capacity)? from the Industry / Business Climate Indicator, and take the average percentage per year). The precise wording of the question for other countries varies slightly, some examples are discussed above. Both plots include the OLS fit, and report the coefficient point estimate, the standard error, and the correlation between the two variables. 


\section{B Model and Quantitative Results}

\section{B.1 Accounting Framework}

The change in real GDP between $t$ and the base period $t-1$ is:

$$
\Delta Y_{n t}=\sum_{j=1}^{J}\left(P_{n j t-1} \Delta Y_{n j t}-P_{n j t-1}^{X} \Delta X_{n j t}\right)
$$

and the proportional change:

$$
\begin{aligned}
\frac{\Delta Y_{n t}}{Y_{n t-1}} & =\frac{\sum_{j=1}^{J}\left(P_{n j t-1} \Delta Y_{n j t}-P_{n j t-1}^{X} \Delta X_{n j t}\right)}{Y_{n t-1}} \\
& =\sum_{j=1}^{J}\left(\frac{\Delta Y_{n j t}}{Y_{n j t-1}} \frac{P_{n j t-1} Y_{n j t-1}}{Y_{n t-1}}-\frac{\Delta X_{n j t}}{X_{n j t-1}} \frac{P_{n j t-1}^{X} X_{n j t-1}}{P_{n j t-1} Y_{n j t-1}} \frac{P_{n j t-1} Y_{n j t-1}}{Y_{n t-1}}\right) \\
& =\sum_{j=1}^{J} D_{n j t-1}\left(\frac{\Delta Y_{n j t}}{Y_{n j t-1}}-\left(1-\eta_{j}\right) \frac{\Delta X_{n j t}}{X_{n j t-1}}\right) .
\end{aligned}
$$

Approximate the growth rate with log difference, and plug in $d \ln Y_{n j t}$ from (3.5):

$$
\begin{aligned}
d \ln Y_{n t} \approx & \sum_{j=1}^{J} D_{n j t-1}\left(d \ln Y_{n j t}-\left(1-\eta_{j}\right) d \ln X_{n j t}\right) \\
= & \sum_{j=1}^{J} D_{n j t-1}\left(d \ln Z_{n j t}+\gamma_{j} \alpha_{j} \eta_{j} d \ln K_{n j t}+\gamma_{j}\left(1-\alpha_{j}\right) \eta_{j} d \ln L_{n j t}\right. \\
& \left.+\gamma_{j}\left(1-\eta_{j}\right) d \ln X_{n j t}-\left(1-\eta_{j}\right) d \ln X_{n j t}\right) \\
= & \sum_{j=1}^{J} D_{n j t-1}\{\underbrace{d \ln Z_{n j t}}_{\operatorname{True~TFP}}+\underbrace{\alpha_{j} \eta_{j} d \ln K_{n j t}+\left(1-\alpha_{j}\right) \eta_{j} d \ln L_{n j t}}_{\text {Primary inputs }} \\
& +\underbrace{\left(\gamma_{j}-1\right) d \ln \left[\left(K_{n j t}^{\alpha_{j}} L_{n j t}^{1-\alpha_{j}}\right)^{\eta_{j}} X_{n j t}^{1-\eta_{j}}\right]}_{=}\} \\
& d \ln Z_{n t}+d \ln \mathcal{I}_{n t},{ }_{\text {Scale effect }}
\end{aligned}
$$


which leads to equation (4.1). This derivation underpins the notion of aggregate TFP (2.4) in Section 2, and the aggregate input-driven component of GDP growth used in Section 4:

$$
d \ln \mathcal{I}_{n t} \equiv \sum_{j=1}^{J} D_{n j t-1}\{\underbrace{\alpha_{j} \eta_{j} d \ln K_{n j t}+\left(1-\alpha_{j}\right) \eta_{j} d \ln L_{n j t}}_{\text {Primary inputs }}+\underbrace{\left(\gamma_{j}-1\right) d \ln \left[\left(K_{n j t}^{\alpha_{j}} L_{n j t}^{1-\alpha_{j}}\right)^{\eta_{j}} X_{n j t}^{1-\eta_{j}}\right]}_{\text {Scale effect }}\}
$$

The Solow residual has the following relationship to gross output and observed inputs:

$d \ln Y_{n j t}=d \ln S_{n j t}+\alpha_{j} \eta_{j} d \ln M_{n j t}+\left(1-\alpha_{j}\right) \eta_{j} d \ln H_{n j t}+\left(1-\alpha_{j}\right) \eta_{j} d \ln N_{n j t}+\left(1-\eta_{j}\right) d \ln X_{n j t}$.

Plugging this way of writing output growth into the real GDP growth equation (B.1), we get the following expression:

$$
d \ln Y_{n t} \approx \sum_{j=1}^{J} D_{n j t-1}\left(d \ln S_{n j t}+\alpha_{j} \eta_{j} d \ln M_{n j t}+\left(1-\alpha_{j}\right) \eta_{j} d \ln H_{n j t}+\left(1-\alpha_{j}\right) \eta_{j} d \ln N_{n j t}\right) .
$$

Comparing (B.3) to (B.5) leads to (2.5), where the utilization adjustment is now:

$d \ln \mathcal{U}_{n t}=\sum_{j=1}^{J} D_{n j t-1}\left\{\left(1-\alpha_{j}\right) \eta_{j} d \ln E_{n j t}+\alpha_{j} \eta_{j} d \ln U_{n j t}+\left(\gamma_{j}-1\right) d \ln \left[\left(K_{n j t}^{\alpha_{j}} L_{n j t}^{1-\alpha_{j}}\right)^{\eta_{j}} X_{n j t}^{1-\eta_{j}}\right]\right\}$.

Setting $\gamma_{j}=1$ (the maintained assumption in Section 2) leads to (2.6).

\section{B.2 Complete Model Equations}

Here we fully specify the quantitative model, which nests our estimation framework, that we use to perform counterfactuals. We assume financial autarky, and that trade is balanced period by period.

Goods and trade Trade is subject to iceberg costs $\tau_{m n j}$ to ship good $j$ from country $m$ to country $n$ (throughout, we adopt the convention that the first subscript denotes source, and the second destination).

The final use in the economy, denoted $\mathcal{F}_{n t} \equiv C_{n t}+\sum_{j} I_{n j t}$, is a Cobb-Douglas aggregate across 
sectors. The functional form and its associated price index are given by

$$
\mathcal{F}_{n t}=\prod_{j} \mathcal{F}_{n j t}^{\omega_{j n}}, \quad P_{n t}=\prod_{j}\left(\frac{P_{n j t}^{f}}{\omega_{j n}}\right)^{\omega_{j n}}
$$

where $\mathcal{F}_{n j t}$ is the final use of sector $j$ in country $n$, and $P_{n j t}^{f}$ is the final use price index in sector $j$ and country $n$. Within each sector, aggregation across source countries is Armington, and the sector price index is defined in a straightforward way:

$$
\mathcal{F}_{n j t}=\left[\sum_{m} \vartheta_{m n j}^{\frac{1}{\rho}} \mathcal{F}_{m n j t}^{\frac{\rho-1}{\rho}}\right]^{\frac{\rho}{\rho-1}}, \quad P_{n j t}=\left[\sum_{m} \vartheta_{m n j} P_{m n j t}^{1-\rho}\right]^{\frac{1}{1-\rho}}
$$

where $\mathcal{F}_{m n j t}$ is final use in $n$ of sector $j$ goods coming from country $m$, and $P_{m n j t}$ is the price of $\mathcal{F}_{m n j t}$. For sector $j$ goods, the expenditure share for final goods imported from country $m$ is given by

$$
\pi_{m n j t}^{f}=\frac{\vartheta_{m n j} P_{m n j t}^{1-\rho}}{\sum_{k} \vartheta_{k n j} P_{k n j t}^{1-\rho}}
$$

The intermediate input usage $X_{n j t}$ is an aggregate of inputs from potentially all countries and sectors:

$$
X_{n j t} \equiv\left(\sum_{m, i} \mu_{m i, n j}^{\frac{1}{\varepsilon}} X_{m i, n j t}^{\frac{\varepsilon-1}{\varepsilon}}\right)^{\frac{\varepsilon}{\varepsilon-1}}, \quad P_{n j t}^{X}=\left[\sum_{m, i} \mu_{m i, n j} P_{m i, n j t}^{1-\varepsilon}\right]^{\frac{1}{1-\varepsilon}}
$$

where $X_{m i, n j t}$ is the usage of inputs coming from sector $i$ in country $m$ in production of sector $j$ in country $n, \mu_{m i, n j}$ is the input coefficient, and where $P_{m i, n j t}$ is the price paid in sector $n, j$ for inputs from $m, i$. This leads to the following share of intermediates from country $m$ sector $i$ in total intermediate spending by $n, j$ :

$$
\pi_{m i, n j t}^{x}=\frac{\mu_{m i, n j} P_{m i, n j t}^{1-\varepsilon}}{\sum_{k, l} \mu_{k l, n j} P_{k l, n j t}^{1-\varepsilon}}
$$

Let $P_{n j t}$ denote the price of output produced by sector $j$ in country $n .^{14}$ No arbitrage in shipping implies that the prices "at the factory gate" and the price at the time of final or intermediate usage are related by:

$$
P_{m i, n j t}=P_{m n i t}=\tau_{m n i} P_{m i t},
$$

\footnotetext{
${ }^{14}$ Note this is not the same as the ideal price index $P_{n j t}^{f}$ of sector $j$ final consumption in $n$, which aggregates imports from the other countries.
} 
where $\tau_{m n i}$ is the iceberg trade cost.

Within a period, the optimal supply of log hours per worker, up to a normalization constant, is given by:

$$
\psi_{j}^{h} \ln H_{n j t}=-\ln \xi_{n j t}+\ln \left(\frac{W_{n j t} L_{n j t}}{P_{n t}}\right),
$$

where "In" denotes a log-deviation from initial equilibrium. The optimal supply of labor effort and capital utilization are

$$
\ln E_{n j t}=\frac{\psi_{j}^{h}}{\psi_{j}^{e}} \ln H_{n j t}, \quad \ln U_{n j t}=\frac{\psi_{j}^{h}}{\psi_{j}^{u}} \ln H_{n j t} .
$$

In a competitive market, primary factors and inputs receive compensation proportional to their share in total input spending. This implies:

$$
\begin{aligned}
R_{n j t} K_{n j t} & =\alpha_{j} \eta_{j} P_{n j t} Y_{n j t} \\
W_{n j t} L_{n j t} & =\left(1-\alpha_{j}\right) \eta_{j} P_{n j t} Y_{n j t} \\
P_{m i, n j t} X_{m i, n j t} & =\pi_{m i, n j t}^{x}\left(1-\eta_{j}\right) P_{n j t} Y_{n j t} .
\end{aligned}
$$

Equilibrium An equilibrium in this economy is a set of goods and factor prices $\left\{P_{n j t}, W_{n j t}, R_{n j t}\right\}$, factor allocations $\left\{M_{n j t}, N_{n j t}, H_{n j t}, E_{n j t}, U_{n j t}\right\}$, and goods allocations $\left\{Y_{n j t}\right\},\left\{C_{n t}, I_{n j t}, X_{m i, n j t}\right\}$ for all countries and sectors such that (i) households maximize utility; (ii) firms maximize profits; and (iii) all markets clear.

At sectoral level, the following market clearing condition has to hold for each country $n$ sector $j$ :

$$
P_{n j t} Y_{n j t}=\sum_{m} P_{m t} \mathcal{F}_{m t} \omega_{m j} \pi_{n m j t}^{f}+\sum_{m} \sum_{i}\left(1-\eta_{i}\right) P_{m i t} Y_{m i t} \pi_{n j, m i t}^{x} .
$$

Meanwhile, a direct implication of financial autarky is that each country's expenditure equals the sum of value added across domestic sectors

$$
P_{m t} \mathcal{F}_{m t}=\sum_{i} \eta_{i} P_{m i t} Y_{m i t}
$$

Combining with equation (B.14), we have

$$
P_{n j t} Y_{n j t}=\sum_{m} \sum_{i} \eta_{i} P_{m i t} Y_{m i t} \omega_{m j} \pi_{n m j t}^{f}+\sum_{m} \sum_{i}\left(1-\eta_{i}\right) P_{m i t} Y_{m i t} \pi_{n j, m i t}^{x} .
$$


Note that once we know the share of value added in production $\eta_{j}$, the expenditure shares $\omega_{m j}, \pi_{n m j t}^{f}$, and $\pi_{n j, m i t}^{x}$ for all $n, m, i, j$, we can compute the nominal output $P_{n j t} Y_{n j t}$ for all country-sector pairs $(n, j)$ after choosing a numeraire good. There is no need to specify all the details of the model.

After linearization, the set of market clearing conditions (B.14) to (B.16) allows us to write the changes in sectoral prices as a function of changes in sectoral outputs, $\ln \mathbf{P}_{t}=\mathcal{P} \ln \mathbf{Y}_{t}$, where both $\mathbf{P}_{t}$ and $\mathbf{Y}_{t}$ are vectors of length $N \times J$.

\section{B.3 Utilization Shock Extraction}

The sectoral output is given by the production function

$$
\begin{aligned}
\ln Y_{n j t}= & \ln Z_{n j t}+\gamma_{j} \eta_{j}\left(\left(1-\alpha_{j}\right)\left(\ln H_{n j t}+\ln E_{n j t}\right)+\alpha_{j} \ln U_{n j t}\right) \\
& +\gamma_{j}\left(1-\eta_{j}\right) \ln X_{n j t}+\gamma_{j} \eta_{j}\left(\alpha_{j} \ln M_{n j t}+\left(1-\alpha_{j}\right) \ln N_{n j t}\right) .
\end{aligned}
$$

When combined with the optimality conditions from households and firms, it leads to

$$
\begin{aligned}
\ln Y_{n j t}= & \ln Z_{n j t}+\gamma_{j} \eta_{j}\left(1-\alpha_{j}\right) \frac{1}{\psi_{j}^{h}}\left(1+\frac{\zeta_{j}}{1-\alpha_{j}}\right)\left(-\ln \xi_{n j t}+\ln P_{n j t}+\ln Y_{n j t}-\ln P_{n t}\right) \\
& +\gamma_{j}\left(1-\eta_{j}\right)\left(\ln Y_{n j t}+\ln P_{n j t}-\ln P_{n j t}^{x}\right)+\gamma_{j} \eta_{j}\left(\alpha_{j} \ln M_{n j t}+\left(1-\alpha_{j}\right) \ln N_{n j t}\right) .
\end{aligned}
$$

Using the relationship between prices and output $\ln \mathbf{P}_{t}=\mathcal{P} \ln \mathbf{Y}_{t}$, we can express the output as a function of the TFP shock, the utilization shock $\ln \xi_{n j t}$, predetermined capital, and predetermined employment

$$
\ln \mathbf{Y}_{t}=\boldsymbol{\Lambda}_{z} \ln \mathbf{Z}_{t}+\boldsymbol{\Lambda}_{\xi} \ln \boldsymbol{\xi}_{t}+\boldsymbol{\Lambda}_{m} \ln \mathbf{M}_{t}+\boldsymbol{\Lambda}_{n} \ln \mathbf{N}_{t} .
$$

Note that hours per worker and output are related in the following way

$$
\psi_{j}^{h} \ln H_{n j t}=-\ln \xi_{n j t}+\ln Y_{n j t}+\ln P_{n j t}-\ln P_{n t} .
$$

It is immediate that hours can also be expressed as

$$
\ln \mathbf{H}_{t}=\Upsilon_{z} \ln \mathbf{Z}_{t}+\Upsilon_{\xi} \ln \boldsymbol{\xi}_{t}+\Upsilon_{m} \ln \mathbf{M}_{t}+\Upsilon_{n} \ln \mathbf{N}_{t}
$$

Since hours, employment and capital are directly observed and TFP is already estimated, the utilization shock $\boldsymbol{\xi}_{t}$ can be computed as a residual. According to our model, the unobserved effort and capital utilization rate are proportional to hours per worker, and it follows that the 
utilization shock rationalizes the estimated variation in utilization.

\section{B.4 Dynamic Responses}

The first-order condition with respect to capital accumulation is

$$
\Psi_{n t}^{\prime}=\beta \mathbb{E}_{t}\left[\Psi_{n t+1}^{\prime}\left(\frac{R_{n j t+1}}{P_{n t+1}} U_{n j t+1}+1-\varrho_{j}\right)\right],
$$

where $\Psi_{n t}^{\prime}$ stands for the marginal utility of final goods consumption in country $n$ period $t$. This condition is similar to the standard Euler equation but is sector-specific and adjusted by the utilization rate.

The optimality condition with respect to $N_{n j t+1}$ is

$$
\mathbb{E}_{t}\left[\Psi_{n t+1}^{\prime}\left(\xi_{n j t} G_{j}\left(H_{n j t+1}, E_{n j t+1}, U_{n j t+1}\right)+\psi^{n} N_{n j t+1}^{\psi^{n}-1}\right)\right]=\mathbb{E}_{t}\left[\Psi_{n t+1}^{\prime} \frac{W_{n j t+1}}{P_{n t+1}} H_{n j t+1} E_{n j t+1}\right]
$$

Note that $N_{n j t+1}$ is chosen in period $t$ before observing shocks in period $t+1$. The left handside is the expected marginal disutility of a unit increase in sector $j$ employment, while the right-hand side is the corresponding marginal utility gain due to higher labor income.

The dynamic model has a large number of state variables (shocks to each country-sector as well as employment and machines in each country-sector), and so cannot be solved exactly. To examine the dynamic responses of the model and how it affects the output correlation, we proceed by solving the log-linearized model. In the linearized model, the taste parameters $\vartheta_{m n j}$ and $\mu_{m i, n j}$ and the trade cost $\tau_{m n i}$ affect the dynamics only via the the final use and the intermediate use trade shares. Once we match the trade shares as in the data, there is no need to pin down the trade costs and taste parameters separately.

The final input into the calibration is shock processes for different countries and sectors. The perceived shock processes matter for the intertemporal decisions of households. We estimate shock processes for the utilization-adjusted TFP shocks. For non-G7 countries, the panel is too short to obtain reliable estimates of the shock processes. Therefore in the dynamic analysis we narrow the focus to the G7 countries, for which we have the longest panel of shocks. We assume that the country-sector technology shocks follow a vector autoregressive process. However, due to the large number of countries and sectors, it is not feasible to estimate the fully unrestricted VAR. Thus, we impose a parsimonious structure on the shock process, that allows for contemporaneous spillovers between country-sectors, but restricts the structure of 
lagged spillovers. The TFP and the utilization shocks shocks are assumed to follow:

$$
\begin{aligned}
\ln Z_{n j t} & =\rho_{n j}^{z} \ln Z_{n j t-1}+\zeta_{n}^{z} \mathbf{1}(m=n, k \neq j) \ln Z_{m k t-1}+\theta_{n j t}^{z}, \\
\ln \xi_{n j t} & =\rho_{n j}^{\xi} \ln Z_{n j t-1}+\zeta_{n}^{\xi} \mathbf{1}(m=n, k \neq j) \ln \xi_{m k t-1}+\theta_{n j t}^{\xi} .
\end{aligned}
$$

That is, we permit a country-sector specific lagged autoregressive parameter, so countrysector shocks can be persistent. We restrict lagged spillovers to be common within a country (across sectors), and zero otherwise. ${ }^{15}$ We allow for a full variance-covariance matrix of the error terms, which amounts to assuming completely unrestricted contemporaneous spillovers: $\boldsymbol{\theta}_{t} \sim \mathcal{N}(\mathbf{0}, \boldsymbol{\Sigma})$, that is, there is a full covariance matrix. The processes (B.18) and (B.19) are estimated separately for each country-sector. Table A8 summarizes the estimation results. The sample variance-covariance matrix of the residuals from estimating equations (B.18) and (B.19) for the period 1978-2007 serves as the estimate of the covariance matrix $\boldsymbol{\Sigma}$ of the shock innovations. We estimate the utilization shock processes in the same way.

The choice of restrictions strikes a balance between relative parsimony, which improves the precision of the parameters estimates, and sufficient flexibility to replicate the measured shock correlations in the data.

TABle A8: Shock Processes: Autoregressive Parameters

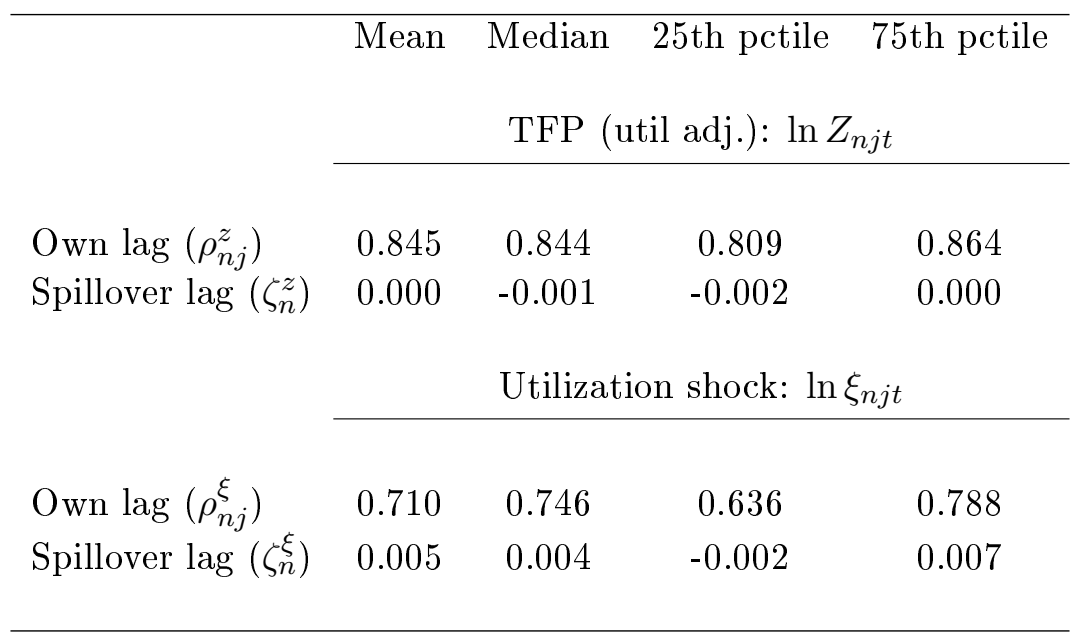

Notes: This table presents results from estimating the shock stochastic processes (B.18)-(B.19). The measures are summary statistics of the coefficients in the sample of sectors and countries.

\footnotetext{
${ }^{15}$ We also experimented with including within-sector spillover terms and dependence on other past variables, but it turns out that most of these terms are not significant.
} 


\section{B.5 Quantitative Results: Sensitivity}

This subsection evaluates sensitivity to alternative elasticities. We also consider a counterfactual analysis where the cross-border trade of intermediate goods is not allowed, which can be thought as muting the role of production network.

Tables A9 and A10 present the results for the static model and dynamic model, respectively. As the estimation of the shock processes requires a relatively long sample, we only consider the G7 countries for the dynamic model analysis. Under lower elasticity of substitution, a country becomes more responsive to production and demand changes in other countries, resulting in more transmission and a higher level of GDP comovements. With a higher composite factor elasticity $\widetilde{\psi}_{j}$, the economy has a stronger amplification channel of the underlying shocks, which also leads to higher GDP comovements. In the dynamic model, the employment elasticity $\psi^{n}$ plays a similar role as the composite factor elasticity. A lower $\psi^{n}$ maps to more elastic employment adjustment, and higher GDP comovements. Though the results vary under these alternative parameter combinations, utilization-adjusted TFP can only generate limited comovement overall.

To assess the role of the production network, we modify the the production structure in the following way: for type $j$ inputs, firms can only source it from domestic firms that produce type $j$ inputs. This can be viewed as setting the transaction costs for intermediate goods usage cross-borders to infinity. As a result, there is no global production network, and the direct international transmission is only through final goods trade. The last block of Table A9 displays the results in the absence of the global production network. The level of GDP comovement is lower, but the magnitude of the change is relatively small. 
Table A9: GDP Growth Correlations in the Static Model and Counterfactuals

All Countries $(\mathrm{N}=406)$

Baseline: $\rho=2.75, \varepsilon=1, \widetilde{\psi}_{j}=0.5$

\begin{tabular}{|c|c|c|c|c|c|c|c|c|}
\hline & mean & median & 25 pctile & 75 pctile & mean & median & 25 pctile & 75 pctile \\
\hline TFP shock & 0.005 & -0.011 & -0.201 & 0.230 & 0.030 & 0.015 & -0.100 & 0.153 \\
\hline Utilization shock & 0.046 & 0.057 & -0.168 & 0.277 & 0.126 & 0.124 & 0.008 & 0.185 \\
\hline ГFP and util. shocks & 0.095 & 0.089 & -0.151 & 0.380 & 0.197 & 0.244 & -0.020 & 0.410 \\
\hline Solow residual & 0.051 & 0.032 & -0.200 & 0.313 & 0.086 & 0.103 & -0.084 & 0.332 \\
\hline
\end{tabular}

Low substitution: $\rho=1, \varepsilon=0.5, \widetilde{\psi}_{j}=0.5$

\begin{tabular}{|c|c|c|c|c|c|c|c|c|}
\hline & mean & median & 25 pctile & 75 pctile & mean & median & 25 pctile & 75 pctile \\
\hline TFP shock & 0.016 & 0.016 & -0.199 & 0.244 & 0.049 & 0.037 & -0.080 & 0.172 \\
\hline Utilization shock & 0.067 & 0.089 & -0.152 & 0.313 & 0.156 & 0.184 & 0.032 & 0.234 \\
\hline TFP and util. shocks & 0.096 & 0.092 & -0.148 & 0.373 & 0.198 & 0.207 & 0.005 & 0.412 \\
\hline Solow residual & 0.061 & 0.038 & -0.179 & 0.317 & 0.126 & 0.165 & -0.032 & 0.357 \\
\hline
\end{tabular}

Elastic factor supply: $\rho=2.75, \varepsilon=1, \widetilde{\psi}_{j}=0.75$

\begin{tabular}{|c|c|c|c|c|c|c|c|c|}
\hline & mean & median & 25 pctile & 75 pctile & mean & median & 25 pctile & 75 pctile \\
\hline TFP shock & 0.012 & 0.005 & -0.202 & 0.243 & 0.038 & 0.018 & -0.081 & 0.165 \\
\hline Utilization shock & 0.049 & 0.053 & -0.173 & 0.280 & 0.128 & 0.113 & 0.001 & 0.208 \\
\hline TFP and util. shocks & 0.111 & 0.096 & -0.141 & 0.434 & 0.282 & 0.307 & 0.039 & 0.449 \\
\hline Solow residual & 0.058 & 0.037 & -0.194 & 0.318 & 0.103 & 0.119 & -0.076 & 0.329 \\
\hline
\end{tabular}

"Max transmission:" $\rho=1, \varepsilon=0.5, \widetilde{\psi}_{j}=0.75$

\begin{tabular}{|c|c|c|c|c|c|c|c|c|}
\hline & mean & median & 25 pctile & 75 pctile & mean & median & 25 pctile & 75 pctile \\
\hline TFP shock & 0.036 & 0.041 & -0.189 & 0.265 & 0.078 & 0.063 & -0.065 & 0.210 \\
\hline Utilization shock & 0.091 & 0.104 & -0.111 & 0.327 & 0.190 & 0.168 & 0.067 & 0.308 \\
\hline TFP and util. shocks & 0.115 & 0.107 & -0.135 & 0.411 & 0.306 & 0.376 & 0.080 & 0.487 \\
\hline olow residual & 0.081 & 0.075 & -0.151 & 0.342 & 0.185 & 0.236 & 0.019 & 0.380 \\
\hline
\end{tabular}

No input network (baseline parameters)

\begin{tabular}{|c|c|c|c|c|c|c|c|c|}
\hline & mean & median & 25 pctile & 75 pctile & mean & median & 25 pctile & 75 pctile \\
\hline TFP shock & 0.001 & -0.005 & -0.214 & 0.242 & 0.028 & 0.021 & -0.124 & 0.152 \\
\hline Utilization shock & 0.032 & 0.044 & -0.197 & 0.270 & 0.120 & 0.147 & -0.014 & 0.185 \\
\hline TFP and util. shocks & 0.071 & 0.071 & -0.181 & 0.346 & 0.122 & 0.133 & -0.090 & 0.327 \\
\hline Solow residual & 0.046 & 0.037 & -0.192 & 0.307 & 0.077 & 0.097 & -0.096 & 0.312 \\
\hline
\end{tabular}

Notes: This table presents the summary statistics of the correlations of the model $d \ln Y_{n t}$ in the full sample for 1995-2007 (left panel), and the G7 countries for 1978-2007 (right panel), in the static model for various elasticity combinations. 
TABle A10: GDP Growth Correlations in the Dynamic Model and Counterfactuals

\begin{tabular}{|c|c|c|c|c|}
\hline Baseline: $\rho=2.75, \varepsilon=1, \widetilde{\psi}_{j}=0.5, \psi^{n}=4$ & mean & median & 25 pctile & 75 pctile \\
\hline TFP shock & 0.002 & -0.005 & -0.175 & 0.178 \\
\hline Utilization shock & 0.132 & 0.099 & -0.010 & 0.218 \\
\hline TFP and utilization shocks & 0.264 & 0.305 & 0.051 & 0.484 \\
\hline Solow residual & 0.065 & 0.081 & -0.128 & 0.285 \\
\hline Low employment elasticity: $\rho=2.75, \varepsilon=1, \widetilde{\psi}_{j}=0.5, \psi^{n}=6$ & mean & median & 25 pctile & 75 pctile \\
\hline TFP shock & 0.007 & -0.018 & -0.186 & 0.168 \\
\hline Utilization shock & 0.125 & 0.091 & -0.018 & 0.195 \\
\hline TFP and utilization shocks & 0.248 & 0.294 & 0.054 & 0.470 \\
\hline Solow residual & 0.067 & 0.079 & -0.114 & 0.294 \\
\hline High employment elasticity: $\rho=2.75, \varepsilon=1, \widetilde{\psi}_{j}=0.5, \psi^{n}=2$ & mean & median & 25 pctile & 75 pctile \\
\hline TFP shock & 0.000 & 0.023 & -0.210 & 0.149 \\
\hline Utilization shock & 0.166 & 0.123 & 0.049 & 0.280 \\
\hline TFP and utilization shocks & 0.304 & 0.369 & 0.093 & 0.513 \\
\hline Solow residual & 0.077 & 0.122 & -0.182 & 0.273 \\
\hline
\end{tabular}

Notes: This table presents the summary statistics of the correlations of the model $d \ln Y_{n t}$ for the G7 countries for 1978-2007 in the dynamic model for various elasticity combinations. 